\title{
Modeling and Analysis on Cushion Characteristics of Fast and High-Flow-Rate Hydraulic Cylinder
}

\author{
Qiwei Lai, Liang Liang, Jing Li, Shijing Wu, and Jun Liu \\ School of Power and Mechanical Engineering, Wuhan University, Wuhan 430072, China \\ Correspondence should be addressed to Shijing Wu; wsj@whu.edu.cn and Jun Liu; liu_jun@whu.edu.cn
}

Received 11 March 2016; Revised 30 June 2016; Accepted 13 July 2016

Academic Editor: Jian Guo Zhou

Copyright (C) 2016 Qiwei Lai et al. This is an open access article distributed under the Creative Commons Attribution License, which permits unrestricted use, distribution, and reproduction in any medium, provided the original work is properly cited.

\begin{abstract}
As an indispensable actuator, the hydraulic cylinder has widespread industrial applications in mechanical engineering. The cushion characteristics of hydraulic cylinder directly affect its performance and reliability, especially the one utilized in hydraulic system with fast response, high flow rate, and instantaneous super power. In order to analyze the cushion characteristics, three different simulation models are established. Furthermore, experiments concerning the pressure characteristics of hydraulic cylinder are accomplished to verify the validation of simulation models. It was found that the integrated simulation model had the highest precision and CFD model showed better pattern of cushion process compared with other models. On the basis of the integrated simulation model, plunger structure and key structural parameters were studied in detail with optimal schemes given. The conical structure, proper design of the diameter of cushion hole, and length of plunger turned out to be effective in promoting the cushion performance. The proposed simulation models and research of cushion structure have scientific and engineering value to promote the innovative development of hydraulic cylinder.
\end{abstract}

\section{Introduction}

Hydraulic cylinder has been widely applied as an important executive component in mechanical engineering [1]. Even though it is popular to employ, the severe hydraulic shock in hydraulic cylinder can easily cause mechanical failure and accident, especially in instantaneous large power hydraulic operating mechanism $[2,3]$. Various cushion schemes of hydraulic cylinder prove to be available to weaken the influence of hydraulic shock. Therefore, the study of cushion characteristics is essential to promote the performance and reliability of hydraulic cylinder.

The cushion scheme of hydraulic cylinder can be basically divided into cushion inside cylinder and cushion outside cylinder. Cushion outside cylinder requires extra control components which make the hydraulic system complicated $[4,5]$. Besides, research mainly focusing on the control strategy requires different control components to fulfil the control task which increases the overall cost [6-8]. Whereas, cushion inside cylinder utilizes the area between cushion plunger and cushion hole to implement cushion process without extra components for simpler structure and less control fault $[9,10]$. The hydraulic cylinder applied in instantaneous large power hydraulic operating mechanism such as ultrahigh voltage (UHV) circuit breaker finishes the stroke in a very short time (about $50 \mathrm{~ms}$ ) driving $200 \mathrm{~kg}$ link transmission mechanism with speed up to more than $10 \mathrm{~m} / \mathrm{s}$. Dealing with the high speed, heavy load, and large quantity of flow, hydraulic cylinder utilized in UHV circuit breaker has more complicated cushion structure compared with common ones [11].

It is of great significance to optimize the hydraulic cylinder structure in order to promote the cushion performance. While the flow field in the process of cushion is complex and changeful, proper modeling is a problem for researching cushion technology. Teng et al. applied derived dynamic equations and compared different machine cushions to prove the new designed machine cushion availability of absorbing impact forces and vibration waves [12, 13]. Wang et al. presented a fuel calibration system and mathematically modeled the system with AMESim simulation of which the numerical result is experimentally verified [14]. Wei et al. estimated the flow characteristics of the cushion structure by Reynolds number and further simulated the cylinder with 
Energy storage system

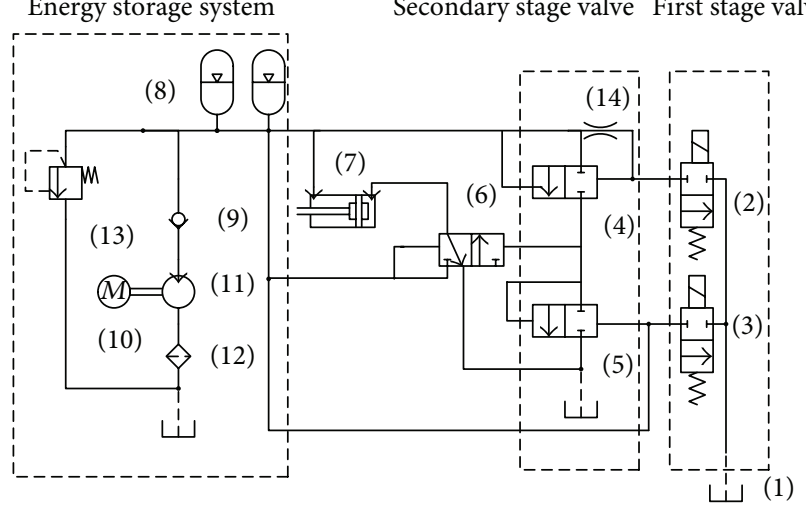

(1) Oil tank

(2) Close action electromagnet valve

(3) Open action electromagnet valve

(4) Close action enlarge valve

(5) Open action enlarge valve

(6) Main valve

(7) Hydraulic cylinder

FIGURE 1: Principle diagram of valve controlling cylinder.

computational fluid dynamics (CFD) analysis method [15]. Ghadimi et al. employed volume of fluid (VOF) simulation to offer the results of the linearized analytical solution with a fully nonlinear and viscous fluid flow solution [16]. Nevertheless, researches about cushion modeling mainly focus either on the analysis of the flow filed or on the whole hydraulic system. Further study needs to be conducted to find a balance between the two major research methods.

The rest of the paper is organized as follows. Section 2 describes the main structure, principle, and mathematical model of the hydraulic cylinder cushion in one certain type of $1100 \mathrm{kV}$ UHV circuit breaker. Then experiments of UHV circuit breaker prototype are accomplished to provide experimental data of pressure in Section 3. Meanwhile, three sets of simulation models (lumped parameter model, integrated simulation model, and CFD simulation model) are built to compare the performances of different models. The optimization of cushion structure is presented in Section 4 to promote the performance of hydraulic operating mechanism. Finally, some conclusions of the work are drawn in Section 5.

\section{System Structure and Principle}

The principle of one fast and high-flow-rate hydraulic cylinder in one certain type of $1100 \mathrm{kV}$ UHV circuit breaker is shown in Figure 1. The whole hydraulic system mainly completes close action and open action which controls the opening and closing of UHV circuit. Once the close action electromagnet valve 9 receives the voltage signal of close action, the control chamber of close action enlarge valve will lose pressure and valve port will open with high pressure oil entering the control chamber of main valve 6. As a result, the main valve spool will move to the close action location and the cushion chamber of hydraulic cylinder 7 will be filled with high pressure oil. Then the piston rod

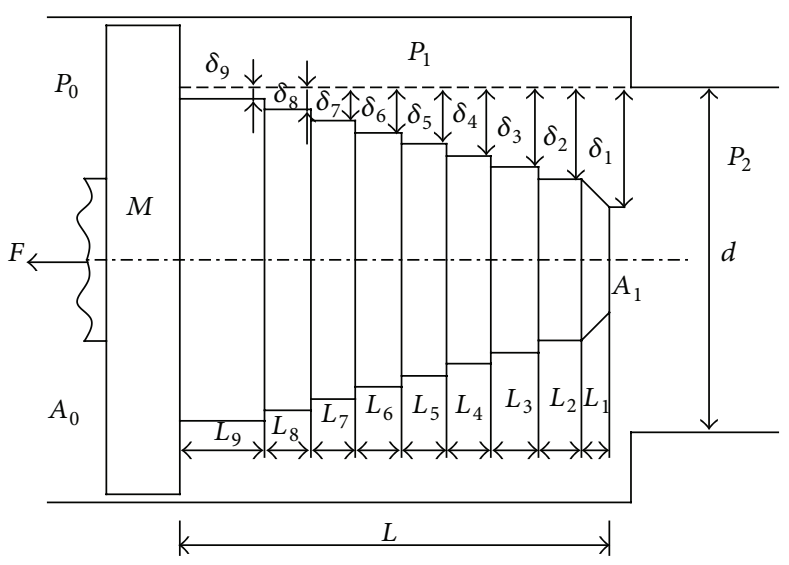

Figure 2: Schematic diagram of hydraulic cylinder structure.

drives link mechanism and moving contact of UHV circuit breaker to finish the close action. Analogously, electromagnet valve 3 and enlarge valve 5 discharge the high pressure oil in control chamber of main valve 6 with spool moving to open action location. Afterwards, the cushion chamber of hydraulic cylinder decompresses and the piston pushed by high pressure oil will drive link mechanism and moving contact of UHV circuit breaker to accomplish the open action.

The schematic diagram of hydraulic cylinder structure is shown in Figure 2. Compared with normal hydraulic cylinder, this one adopts more intricate and complicated structure with 9 steps.

In Figure 2, $d$ is the diameter of cushion hole, $L$ is the total length of cushion plunger, $L_{1} \sim L_{9}$ are the lengths of the steps, $\delta_{1} \sim \delta_{9}$ are the fit gaps between the step and cushion hole, $P_{0}$ is the working pressure, $P_{1}$ is the pressure in cushion chamber, $P_{2}$ is the pressure in plunger chamber, $M$ is the equivalent mass of transmission mechanism, $F$ is the load force exerted on the head of transmission mechanism, and $A_{1}$ and $A_{2}$ are the effective bearing pressure area of the two chambers.

As for the basic process of hydraulic cylinder cushion, there are three stages as local pressure loss, sharp edge throttling, and aperture throttling as shown in Figure 3. The local pressure loss stage is caused by the sudden contraction of the flow channel at the start of cushion process. The pressure loss at the edge of cushion plunger and cushion hole forms the sharp edge throttling stage while the cushion plunger entering the cushion hole means the start of aperture throttling stage [17].

(1) When the cushion plunger is far away from the cushion hole, oil in the cushion chamber discharges through the cushion hole. As the section of flow channel suddenly contracts, local pressure loss is generated. The quantity of flow equation is as follows:

$$
Q_{j}=C_{f} \frac{\pi d^{2}}{4} \sqrt{\frac{2}{\rho} \Delta p},
$$

where $C_{f}$ is discharge coefficient of the sudden contraction of the flow channel determined by the ratio of area before and 


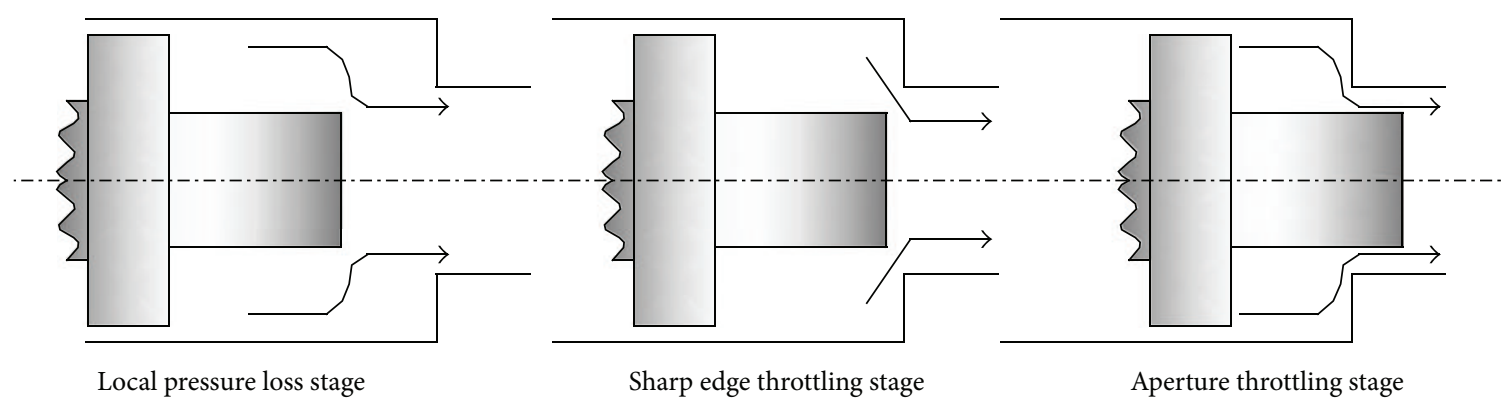

FIGURE 3: Three stages of cushion process.

after the contractive flow channel, $d$ is diameter of cushion hole, and $\Delta p$ is differential pressure between the contractive sections equaling the pressure in cushion chamber minus the pressure in plunger chamber.

(2) Once the cushion plunger approaches the cushion hole, the edge of the plunger and edge of plunger chamber will form into sharp edge throttling. The quantity of flow equation is as follows:

$$
Q_{r}=C_{d} d \pi \sqrt{\left(l_{0}-x\right)^{2}+\delta^{2}} \sqrt{\frac{2}{\rho} \Delta p},
$$

where $C_{d}$ is discharge coefficient of the sharp edge throttling, $l_{0}$ is distance between the plunger and cushion hole at the beginning, $x$ is displacement of plunger, and $\delta$ is fit gap between the cushion plunger and cushion hole.

(3) After the cushion plunger enters the cushion hole, the aperture throttling stage begins. The flow equation is based on the step structure of the cushion structure. On the condition that the $N$ th steps have already accessed into the cushion hole while part of the $(N+1)$ th step entered, the quantity of flow equation is as follows:

$$
Q_{f}=\frac{\pi d \Delta p}{\left[12 \mu \sum_{i=1}^{N}\left(l_{i} / \delta_{i}^{3}+\left(x-l_{0}-\sum_{i=1}^{N} l_{i}\right) / \delta_{i+1}^{3}\right)\right]},
$$

where $l_{i}$ is length and $\delta_{i}$ is the fit gap between the cushion plunger and hole when the $i$ step enters the cushion hole.

In an effort to describe the two transition points of the three stages, the paper considers the following:

(1) As the plunger moves, the flow quantity calculated from the sharp edge throttling stage begins to diminish. When it is less than or equal to the flow quantity calculated from the local pressure loss stage, the sharp edge throttling stage is assumed to take place:

$$
C_{d} d \pi \sqrt{\left(l_{0}-x\right)^{2}+\delta^{2}} \sqrt{\frac{2}{\rho} \Delta p} \leq C_{f} \frac{\pi d^{2}}{4} \sqrt{\frac{2}{\rho} \Delta p} .
$$

(2) Similarly, if the flow quantity calculated from the aperture throttling stage is less than or equal to the flow from sharp edge throttling, the aperture throttling stage is considered to begin:

$$
\begin{gathered}
\frac{\pi d \Delta p}{\left[12 \mu \sum_{i=1}^{N}\left(l_{i} / \delta_{i}^{3}+\left(x-l_{0}-\sum_{i=1}^{N} l_{i}\right) / \delta_{i+1}^{3}\right)\right]} \\
\leq C_{d} d \pi \sqrt{\left(l_{0}-x\right)^{2}+\delta^{2}} \sqrt{\frac{2}{\rho} \Delta p .}
\end{gathered}
$$

The values of $x$ obtained from the calculation through (4) and (5) are the location of the two transition points.

Equations (1) (3) describe the change pattern of flow quantity during the three stages. However, corresponding flow continuity equations and equilibrium equations are needed to solve the above equations. The flow continuity equation of cushion chamber at the local pressure loss stage is

$$
Q_{j c}=\frac{d V_{1}}{d t}-\frac{V_{1}}{\beta_{e}} \cdot \frac{d P_{1}}{d t}=\left(A_{1}+A_{2}\right) \dot{x}-\frac{V_{1}}{\beta_{e}} \cdot \frac{d P_{1}}{d t} .
$$

At the sharp edge throttling stage and aperture throttling stage, the flow continuity equation is

$$
Q_{d c}=\frac{d V_{1}}{d t}-\frac{V_{1}}{\beta_{e}} \cdot \frac{d P_{1}}{d t}=A_{1} \dot{x}-\frac{V_{1}}{\beta_{e}} \cdot \frac{d P_{1}}{d t},
$$

where $V_{1}$ is the volume of cushion chamber and $\beta_{e}$ is the bulk modulus of elasticity.

The flow continuity equation of plunger chamber at the local pressure loss stage is

$$
Q_{j p}=\frac{V_{2}}{\beta_{e}} \cdot \frac{d P_{1}}{d t}+C_{d p} A v \sqrt{\frac{2 P_{2}}{\rho}} .
$$

At the sharp edge throttling stage and aperture throttling stage, the flow continuity equation is

$$
Q_{d p}=\frac{V_{2}}{\beta_{e}} \cdot \frac{d P_{1}}{d t}-A_{2} \dot{x}+C_{d p} A_{v} \sqrt{\frac{2 P_{2}}{\rho}},
$$

where $V_{2}$ is the volume of plunger chamber, $C_{d p}$ is the shrinkage coefficient of contraction, and $A_{v}$ is the orifice area of plunger chamber. 

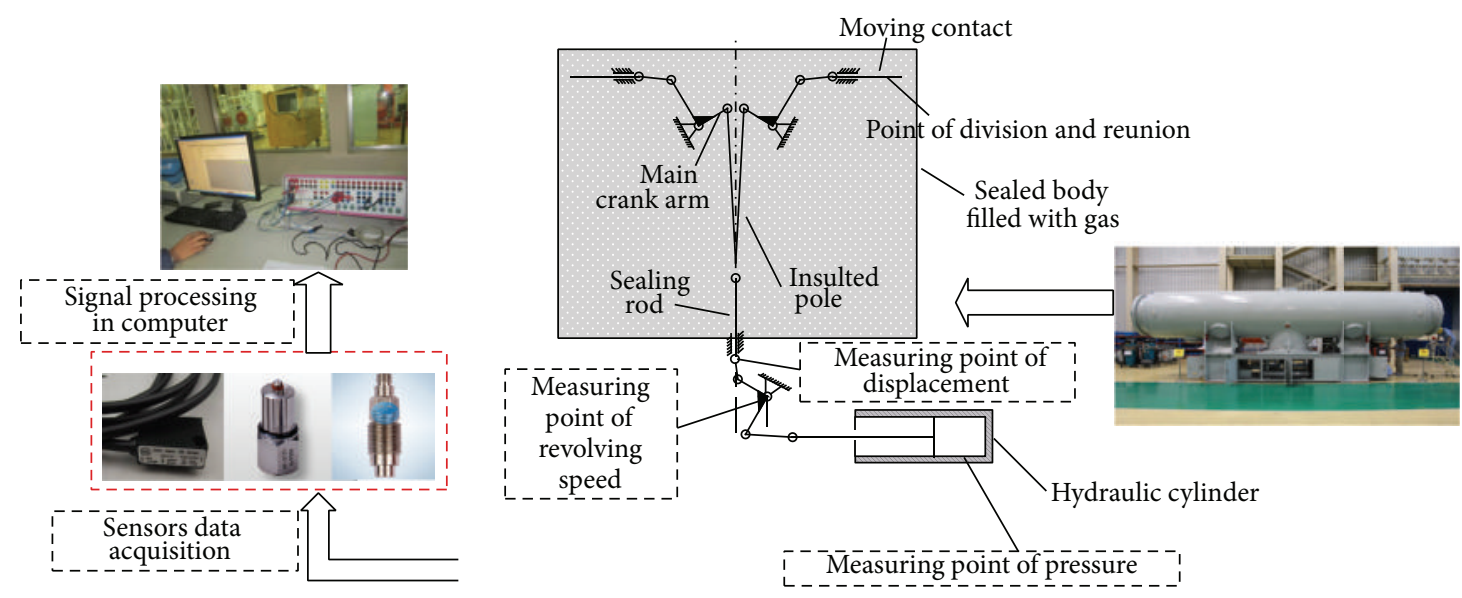

FIgURE 4: Test apparatus of UHV circuit breaker.

In the process of cushion, the dynamic motion of the piston can be derived as follows:

At the local pressure loss stage:

$$
M \ddot{x}=P_{0} A_{0}-P_{1} A_{1}-P_{1} A_{2}-F-B \dot{x} .
$$

At the sharp edge throttling stage and aperture throttling stage:

$$
M \ddot{x}=P_{0} A_{0}-P_{2} A_{1}-P_{2} A_{2}-F-B \dot{x},
$$

where $B$ is the viscous damping coefficient.

\section{Experiment and Simulation}

3.1. Test Apparatus. In order to evaluate the performance of the hydraulic operating mechanisms for UHV circuit breakers, experiments on prototype have been accomplished. On account of the entire components above the sealing rod in the sealed body filled with gas, the dynamic characteristics of moving contact can be obtained by conversion of characteristics of nonsealed components. There are two key parameters measured in experiments as follows.

(1) Displacement of Sealing Rod. Due to the high speed of mechanism motion and possible vibration, magnetic railings ruler is applied to test the displacement of sealing rod.

(2) Pressure in Cushion Chamber. Piezoelectric sensor is installed on the hydraulic cylinder which has high sensitivity, strong shock resistance, wide operating temperature range, long life, and reliable working condition.

The whole test apparatus is shown in Figure 4.

The original test data curves have obvious ripple as there exist gaps in link transmission mechanism, elastic deformation, hydraulic shock, and measuring error. Thus signal processing is utilized to express the nonlinear test data more accurately by basically removing the fluctuation caused by error signal. The processed experimental data of pressure is helpful for further validation of simulation model.

\subsection{Simulation Model}

3.2.1. Lumped Parameter Model of Hydraulic Cylinder. According to the state equations of lumped parameter (1) (10), numerical computation model of hydraulic cylinder cushion has been built in MATLAB/Simulink as shown in Figure 5.

The ode15s (stiff/NDF) solver is chosen. The step size is set to autovariable step with 5 th order as the maximum order of numerical partial differential equations. After solving the lumped parameter model, the dynamic pressure characteristics of hydraulic cylinder are obtained as theoretical results to compare with other simulation models.

\subsubsection{Integrated Simulation Model of Hydraulic Operating} Mechanism. As shown in Figures 1 and 4, the hydraulic cylinder functions under the influence of the linkage mechanism and other hydraulic components in the hydraulic operating mechanism. Therefore, it is more practical to build an integrated simulation model taking all the components into consideration. The principle of physical coupling between different components models is shown in Figure 6.

When the electromagnet valve receives the open or close action signal current, the hydraulic components begin to act which can be described as

$$
m_{e} \ddot{x}_{e}=F_{e}-b_{e} \dot{x}_{e}-F_{s e}
$$

where $m_{e}$ is the electromagnet mass, $x_{e}$ is the displacement of solenoid, $F_{e}$ is the electromagnet output force, $b_{e}$ is the viscous friction coefficient, and $F_{s e}$ is the solenoid spring force.

The dynamics motion models of hydraulic components are described as

$$
\begin{aligned}
m_{f} \ddot{x}_{f}= & F_{f}+\sum p_{\mathrm{pc}} A_{\mathrm{pc}}-\sum p_{\mathrm{nc}} A_{\mathrm{nc}}-F_{v}-F_{f i}-F_{s} \\
& -F_{\mathrm{sc}},
\end{aligned}
$$

where $m_{f}$ is the moving mass of hydraulic components, $x_{f}$ is the displacement of moving mass, $F_{f}$ is the flow force, $p_{\mathrm{pc}}$ is the positive control chamber pressure in hydraulic system, $A_{\mathrm{pc}}$ is the area of positive control chamber, $p_{\mathrm{nc}}$ is the negative 


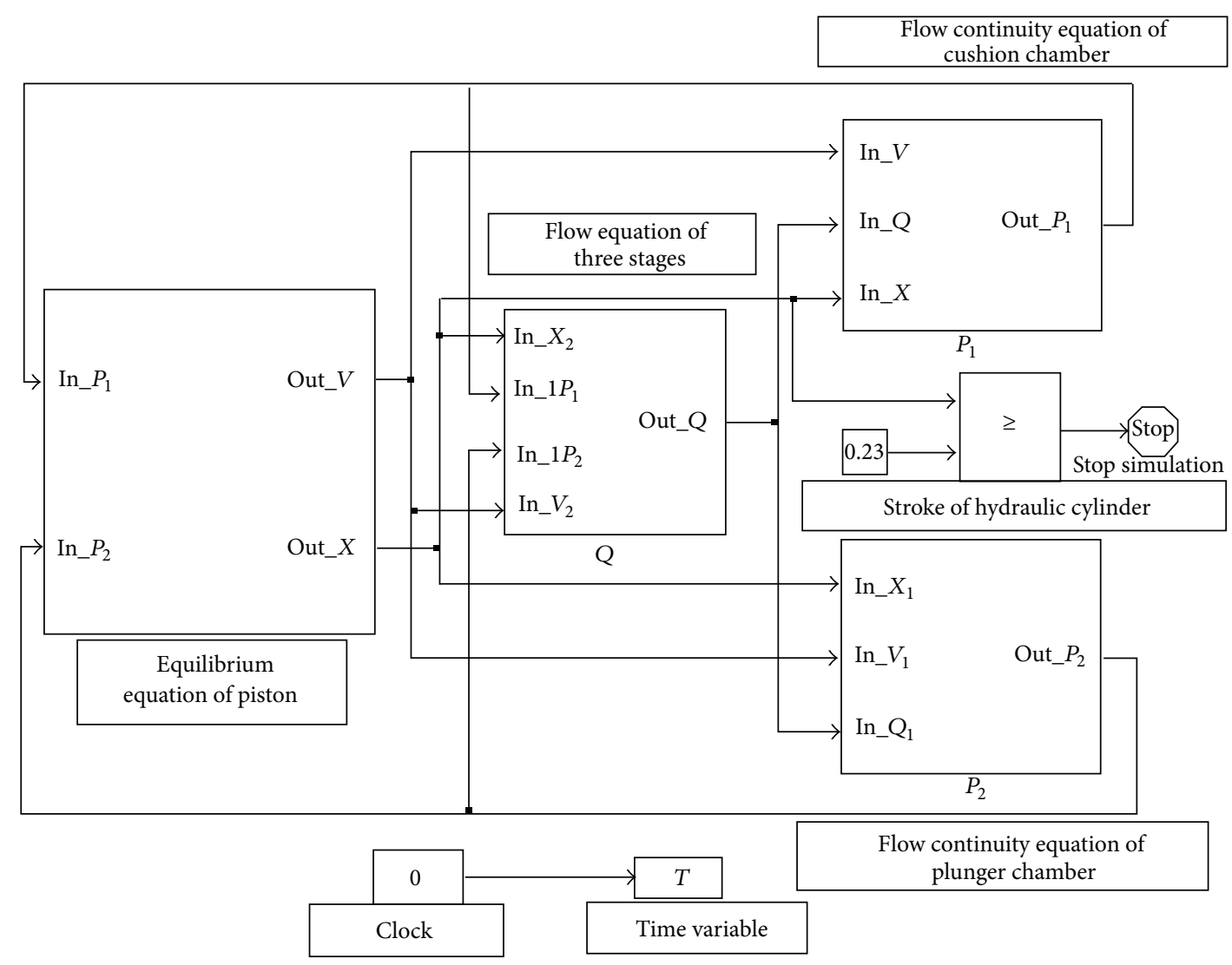

FIGURE 5: Lumped parameter model of hydraulic cylinder in MATLAB/Simulink.

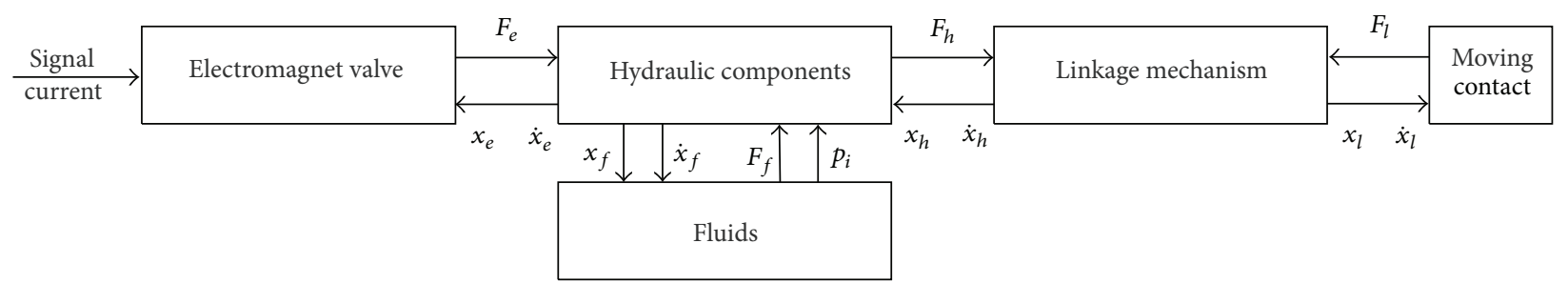

Figure 6: Coupling principle of integrated model.

control chamber pressure in hydraulic system, $A_{\mathrm{nc}}$ is the area of negative control chamber, $F_{v}$ is the viscous damping force, $F_{f i}$ is the flow force of different hydraulic components, $F_{s}$ is the spring force, and $F_{s c}$ is the static/coulomb friction.

The linkage mechanism converts the output force, the velocity, and the displacement of the hydraulic cylinder to the moving contact which can be described as

$$
m_{l} x_{l}=k_{l}\left(F_{h}-F_{c}\right)-F_{l},
$$

where $m_{l}$ is the moving contact mass, $x_{l}$ is the moving contact displacement, $k_{l}$ is the force transmission ratio of linkage mechanism, $F_{h}$ is the output force of hydraulic cylinder, $F_{c}$ is the cushion force, and $F_{l}$ is the reaction force of moving contact.

Based on mathematical principle of all the components in hydraulic operating mechanisms and coupling principle (12)(14) for UHV circuit breaker, the integrated simulation model is developed in AMESim as shown in Figure 7. This integrated model considers mutual dynamic effects of three-stage valve, accumulator, and pipeline system along with compressibility of oil. Standard variable step size dynamical-integral solver is utilized. The total computation time is set to $0.2 \mathrm{~s}$. Meanwhile, the data export and recording time interval are set to $10^{-7} \mathrm{~s}$. The main parameters of simulation are listed in Table 1.

3.2.3. CFD Simulation Model of Cylinder Cushion. All above simulation models can only acquire lumped parameter value of pressure in cushion chamber which reveals the pressure characteristics. Nevertheless, the oil in cushion chamber flows constantly which generates complicated flow field. In addition, there exist pressure gradient and velocity gradient in cushion chamber and plunger chamber. In this case, CFD analytical technology can be applied to obtain the pressure 


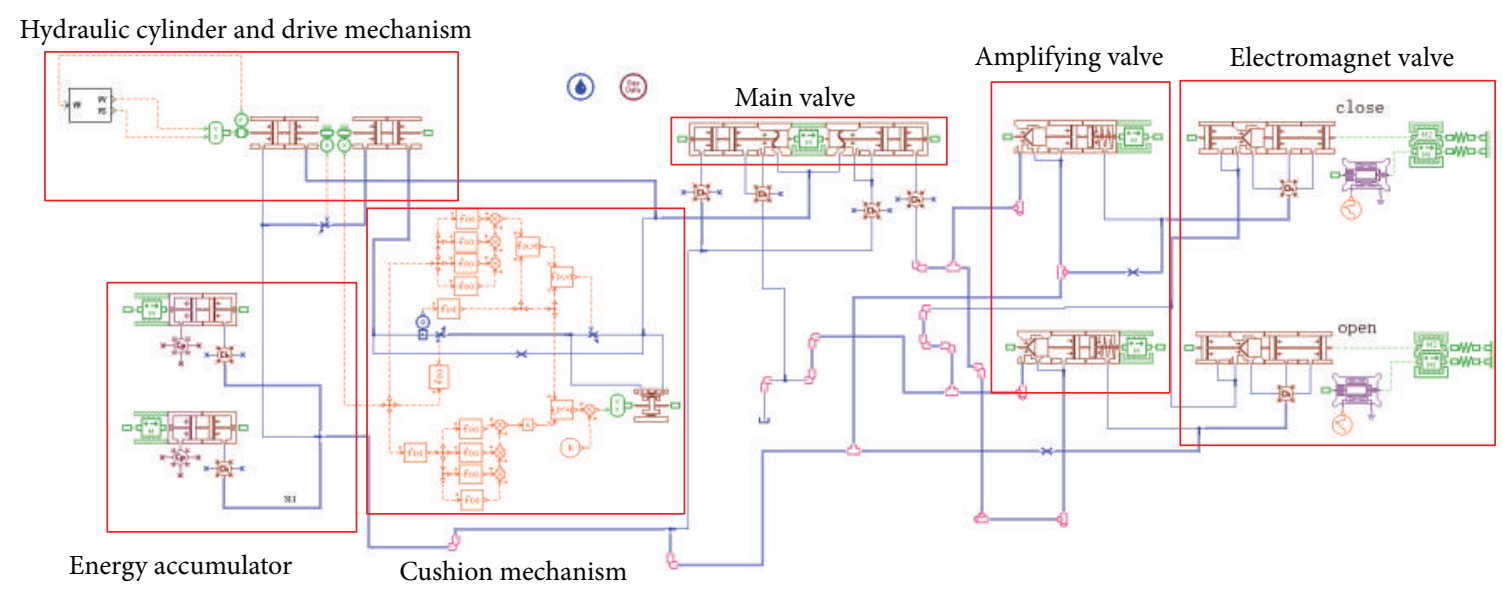

FIGURE 7: Integrated simulation model of hydraulic operating mechanism.

TABLE 1: Main parameters in simulation calculation.

\begin{tabular}{lc}
\hline Parameters & Value \\
\hline Density of oil $\rho\left(\mathrm{kg} / \mathrm{m}^{3}\right)$ & 850 \\
Dynamic viscosity of oil $\mu(\mathrm{Pa} \cdot \mathrm{s})$ & 0.025 \\
Bulk modulus of elasticity $\beta_{e}(\mathrm{MPa})$ & 700 \\
Supply pressure of oil $P_{0}(\mathrm{MPa})$ & 32.6 \\
Diameter of main pipeline $d_{0}(\mathrm{~mm})$ & 0.04 \\
$\begin{array}{l}\text { Discharge coefficient of the sudden contraction of the } \\
\text { flow channel } C_{f}\end{array}$ & 0.731 \\
$\begin{array}{l}\text { Discharge coefficient of the sharp edge throttling } C_{d} \\
\text { Initial volume of cushion chamber } V_{0}\left(\mathrm{~m}^{3}\right)\end{array}$ & 0.67 \\
$\begin{array}{l}\text { External diameter of piston } D(\mathrm{~m}) \\
\text { Diameter of piston } d(\mathrm{~m})\end{array}$ & 0.0033 \\
$\begin{array}{l}\text { Stroke of cylinder } L_{s}(\mathrm{~m}) \\
\begin{array}{l}\text { Effective bearing pressure area of working chamber } A_{1} \\
\left(\mathrm{~m}^{2}\right)\end{array}\end{array}$ & 90 \\
$\begin{array}{l}\text { Effective bearing pressure area of cushion chamber } A_{2} \\
\left(\mathrm{~m}^{2}\right)\end{array}$ & 0.0048 \\
\hline
\end{tabular}

and velocity distribution in hydraulic cylinder which can be compared with lumped parameter simulation to further research the cushion characteristics of hydraulic cylinder $[18,19]$. As the oil in hydraulic cylinder is considered to be compressible viscous fluid with constant viscidity, the basic principle of applying the CFD method can be described as follows:

(1) Mass conservation equation:

$$
\frac{\partial}{\partial t} \iiint_{\mathrm{vol}} \rho d x d y d z+\oiint_{A} \rho v \cdot n d A=0,
$$

where vol is the control volume and $A$ is the control surface.

(2) Momentum conservation equation:

$$
\rho \frac{d v}{d t}=\rho F-\operatorname{grad} p+\frac{\mu}{3} \operatorname{grad}(\operatorname{div} v)+\mu \nabla^{2} v .
$$

The computational domain changing process of hydraulic cylinder cushion is shown in Figure 8. Considering the present hydraulic cylinder geometry, full-scale simulation of the hydraulic cylinder has been implemented in the $2 \mathrm{D}$ axisymmetric swirl model to save computational time and resources as shown in Figure 9. The following model was constructed using ICEM CFD 15.0 and simulated using FLUENT 15.0 software.

On account of big difference between the size of steps and size of hydraulic cylinder, the mesh should be divided into different parts with local domain in dense mesh. Through multiple schemes of mesh method, mixing type of quadrangle and triangle unstructured grid is utilized.

By applying dynamic mesh technology in this case, the calculation domain is split into several faces with interfaces connected. As a result, there will not be mutual affection from different meshes and nodes. Furthermore, the meshes near the steps in face 2 should be divided elaborately as the irregular structure and small size. For the sake of accuracy of calculation, the number of mesh nodes around the steps was increased from 10 to 40 to ensure that the calculation results were mesh-independent. The corresponding results of mesh sensitivity analysis are shown in Figure 10. It is found that the number of nodes does not affect the results of the peak pressure beyond 30. For other step diameters in our simulation, the number of nodes can be chosen proportionally according to above results. The final mesh is shown in Figure 11 with 67641 cells and 52176 nodes.

After meshing in different faces, 6DOF model is utilized to obtain dynamic characteristics of plunger without designation of motion law of plunger. UDF (user-defined function) is applied to give the value of mass, rotational inertia, and location of centroid. Then the viscous model is set to SST $k$-omega and dynamic mesh option is chosen with layering mesh methods. The time step is set with variable time step by Events function which guarantees the accuracy of calculation and saves unnecessary calculation time. While the convergence precision is set to $1 \times 10^{-6}$, the total time step is assigned to be 10000 with 500 maximum iterations per step. 


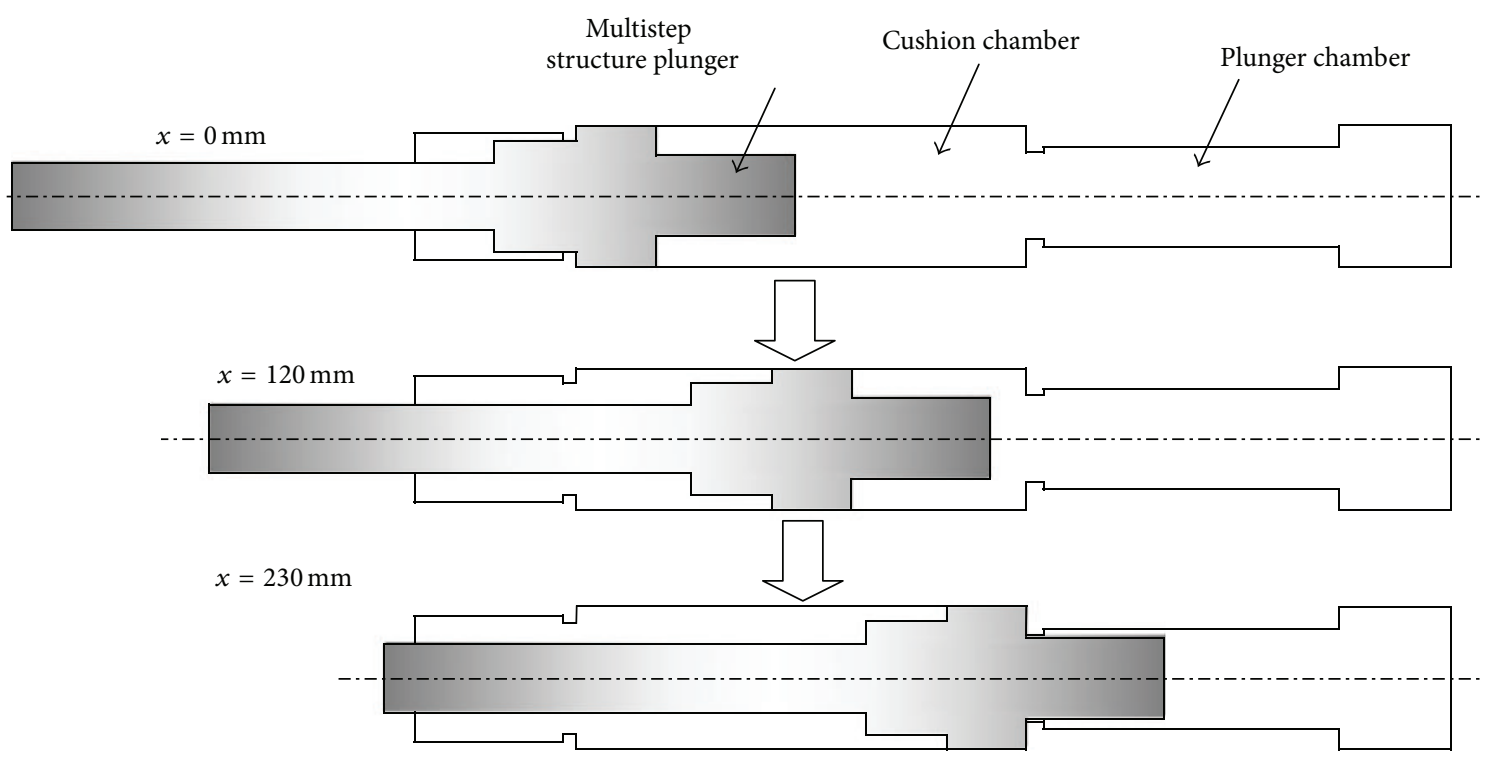

FIGURE 8: Changing process of computational domain during cylinder cushion.

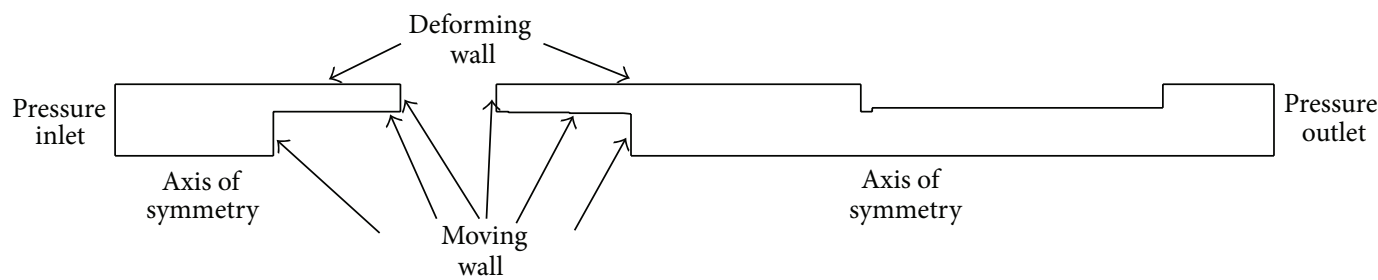

FIGURE 9: Boundary condition.

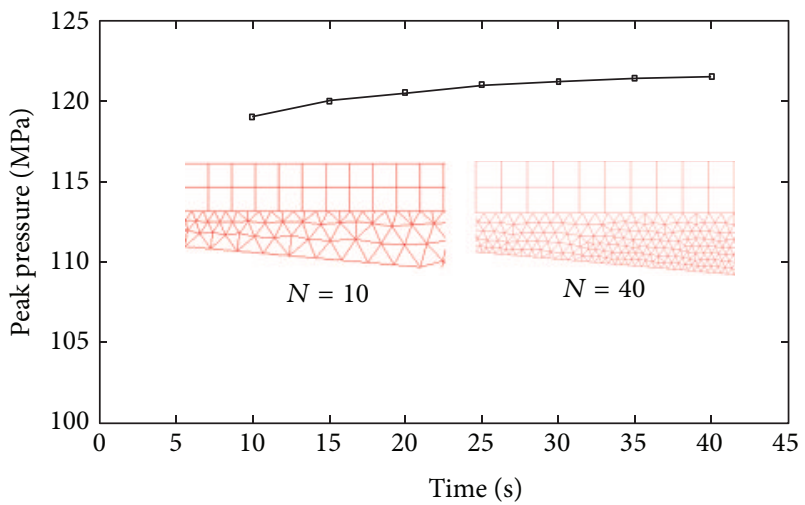

FIGURE 10: Number of nodes around the first step.

\subsection{Simulation Results and Discussion}

3.3.1. Simulation Results of Cushion Process. The results obtained from the postprocessing of the Fluent simulation are recorded to analyze the whole cushion process in hydraulic cylinder. A series of typical variations of pressure distribution and velocity vectors are shown as follows.

(1) When $t=0.00001 \mathrm{~s}$, the pressure distribution and velocity vectors are shown in Figure 12.

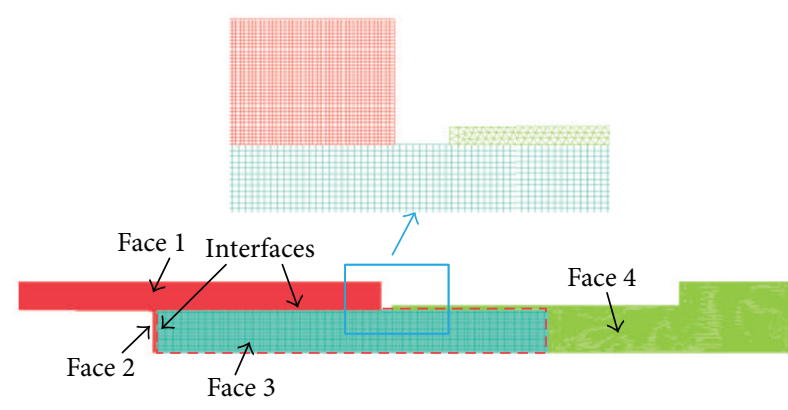

FIGURE 11: Final mesh scheme.

At the start of cushion process as local pressure loss stage, the plunger is far away from the cushion chamber. The flow field is steady with even pressure gradient. The highest pressure exists in the left part of cushion chamber.

(2) When $t=0.01 \mathrm{~s}$, the pressure distribution and velocity vectors are shown in Figure 13.

The pressure distribution shows that the cushion process is still at the local pressure loss stage, whereas the plunger is close to the cushion chamber and the pressure gradient begins to concentrate on the cushion chamber. The maximum pressure tends to fill the cushion chamber. 

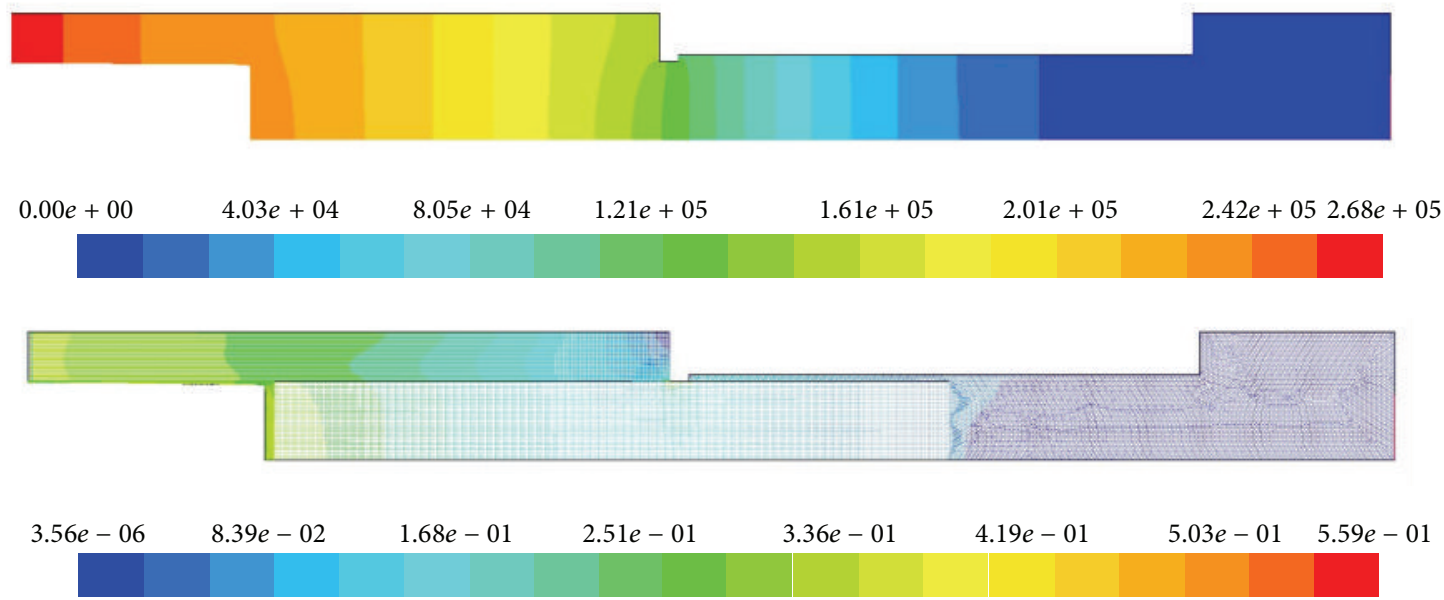

FIGURE 12: Pressure distribution and velocity vectors in hydraulic cylinder when $t=0.0001 \mathrm{~s}$.
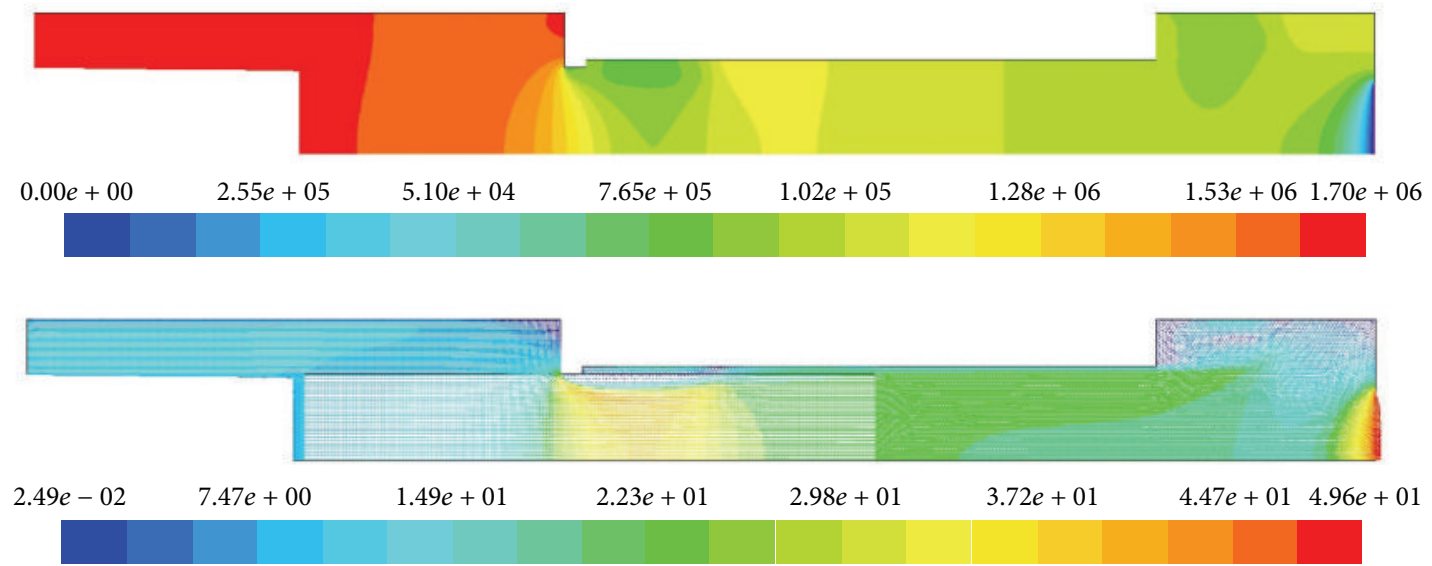

FIGURE 13: Pressure distribution and velocity vectors in hydraulic cylinder when $t=0.01 \mathrm{~s}$.

(3) When $t=0.02 \mathrm{~s}$, the pressure distribution is shown in Figure 14 .

The plunger has not entered the oil plunger chamber when the cushion process enters the sharp edge throttling stage. The throttle surface forms into a conical face lying between plunger and cylinder wall as shown in Figure 15. The pressure gradually drops from the cushion chamber to oil plunger chamber while the velocity direction is perpendicular to the conical face.

(4) When $t=0.025 \mathrm{~s}$, the pressure distribution is shown in Figure 16.

At this time, the first step enters cushion chamber with the entire cushion chamber in maximum pressure. The throttle surface is still a conical face as shown in Figure 17.

(5) When $t=0.035 \mathrm{~s}$, the local pressure distribution and velocity vectors are shown in Figure 18.

Part of the second step has already entered the cushion chamber. The throttle surface at the second step is a conical face while the throttle surface between the cushion chamber and first step is an anchor ring.
The CFD analysis fits well with the theoretical analysis of the three stages of cushion process, whereas the CFD calculation results show that the sharp edge stage and aperture throttling stage both exit when the step enters the cushion chamber. Thus the effect on the plunger of both sharp edge stage and aperture throttling stage should be considered during the whole cushion process.

3.3.2. Validation of the Pressure Characteristics. The pressure characteristics in cushion chamber during open action are shown in Figure 19 from calculation results of different simulation models and test data.

The pressure curve from lumped parameter model has roughly similar tendency compared to test data. The difference may be caused by the ignorance of compressibility and simultaneous coexistence of different cushion stages. Although the lumped parameter model is not suitable for analysis of pressure characteristics, it can be applied to analyze the cushion process grossly. 


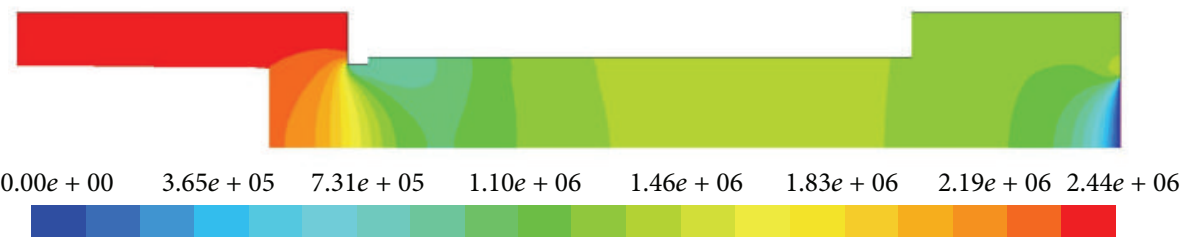

FIGURE 14: Pressure distribution in hydraulic cylinder when $t=0.02 \mathrm{~s}$.

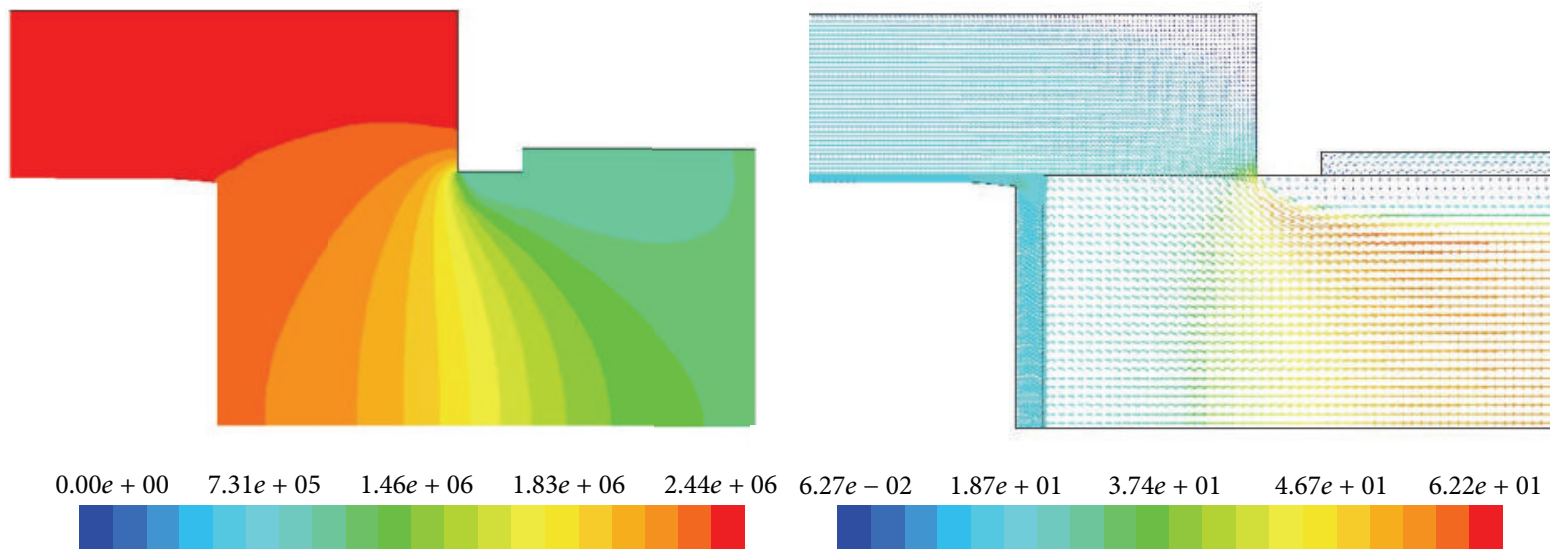

FIGURE 15: Local pressure distribution and velocity vectors in hydraulic cylinder when $t=0.02 \mathrm{~s}$.

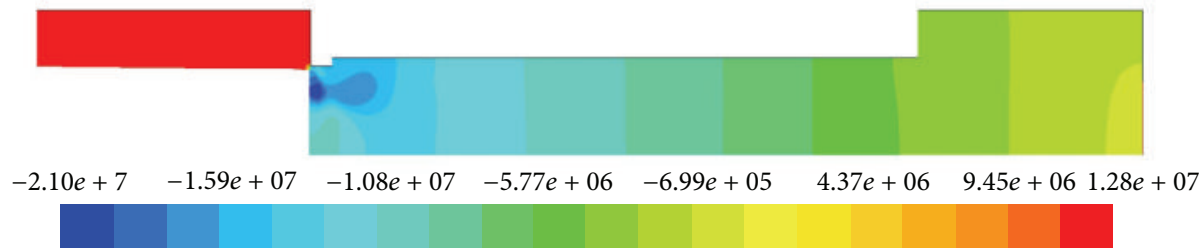

FIGURE 16: Pressure distribution in hydraulic cylinder when $t=0.025 \mathrm{~s}$.
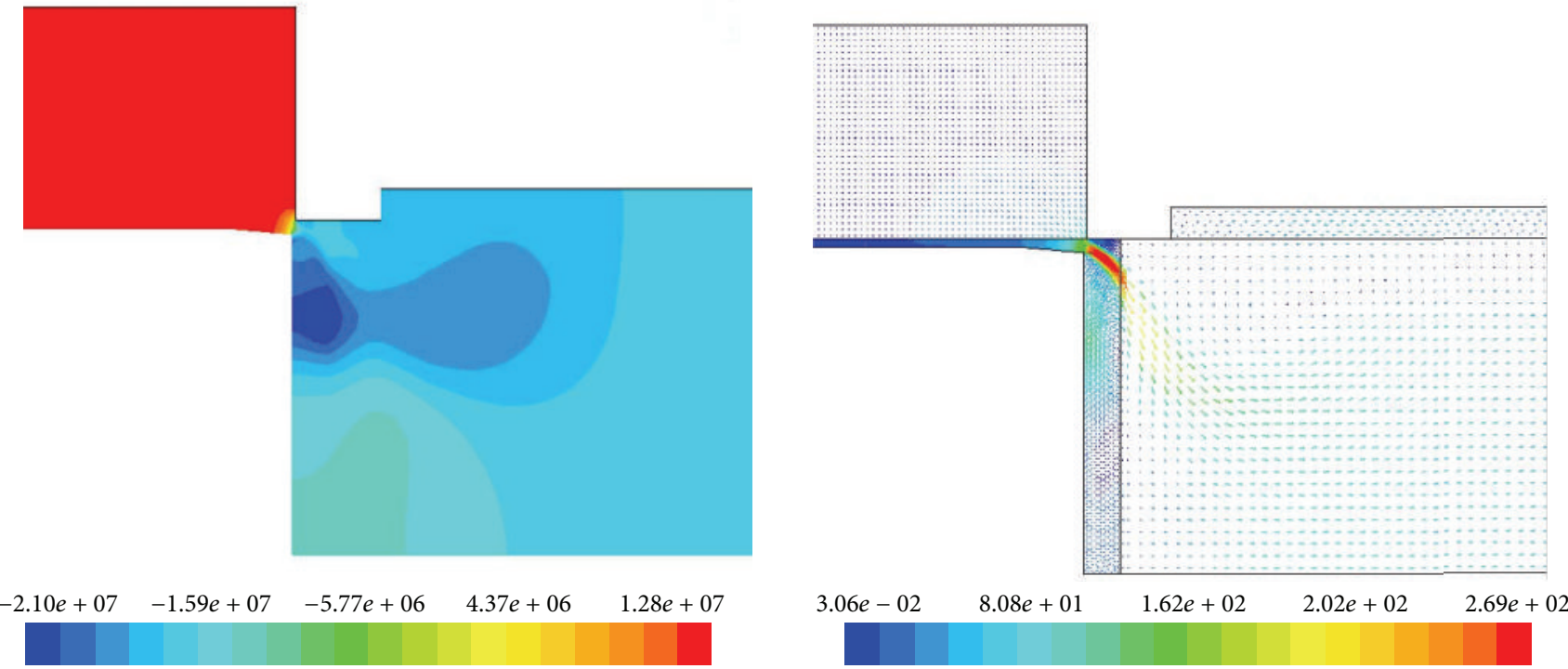

FIGURE 17: Local pressure distribution and velocity vectors in hydraulic cylinder when $t=0.025 \mathrm{~s}$. 


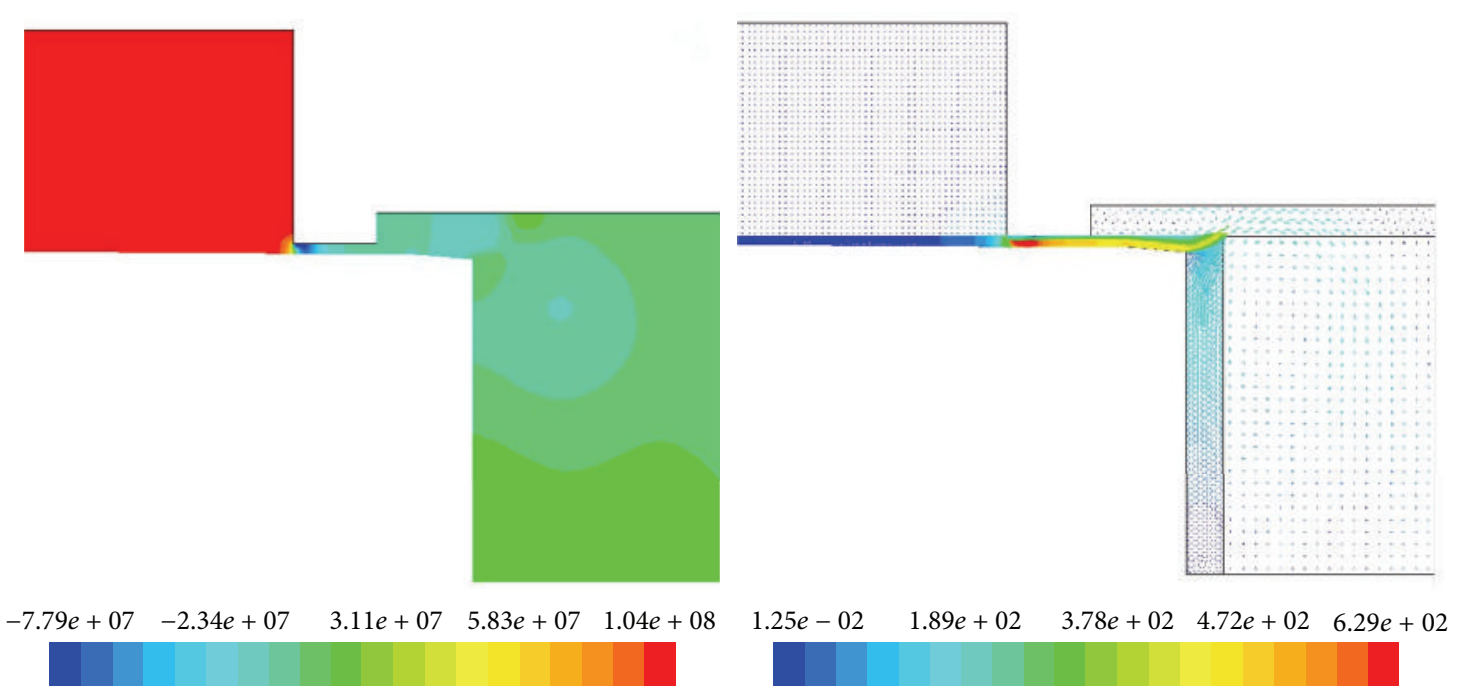

FIGURE 18: Local pressure distribution and velocity vectors in hydraulic cylinder when $t=0.035 \mathrm{~s}$.

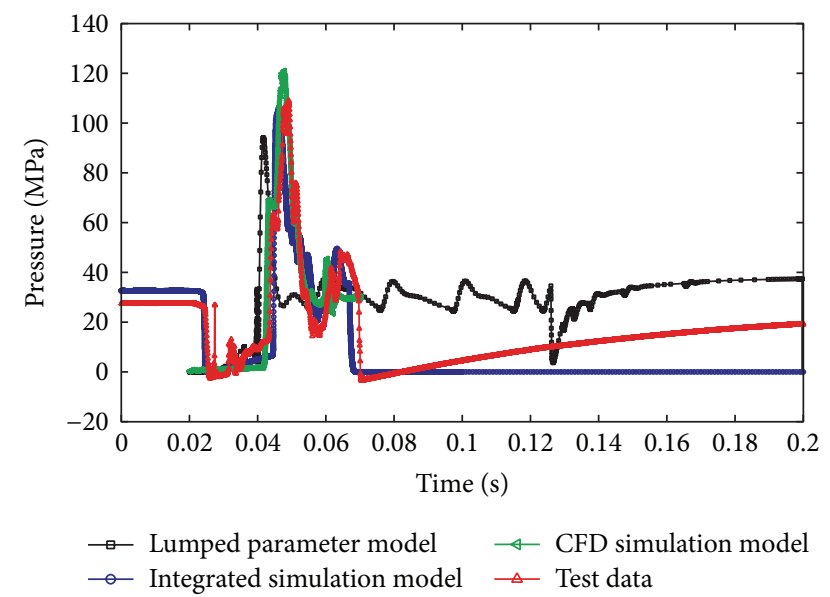

FIGURE 19: Pressure characteristics from different simulation models and test data.

The pressure curve of integrated model resembles the test data which can reveal the phasic process of energy transmission during cushion. The existing of curve offset compared to test data may be caused by the delay of electrical signal during real test and errors caused by multiple tests. As the integrated model can simulate the pressure characteristics, it can be applied to further study the characteristics of hydraulic cylinder.

Despite the CFD model having less similar pressure curve than the integrated model, it also fits well with the tendency of test data. In addition, the pressure curve from CFD model has resemblance to the pattern of pressure fluctuation when the plunger enters the cushion chamber.

3.3.3. Comparisons between Different Simulation Models. The three simulation models, as complex as the flow field in cushion chamber, have their own advantages and disadvantages as shown in Table 2. Although the lumped parameter model has the lowest accuracy, it can be applied for quick calculation of the peak pressure. Meanwhile, the pressure curve of integrated simulation model is more similar to the test data than the other models on the whole from the comparison of different simulation models and test data. The major reason for the deviation of curves from the lumped parameter model and CFD simulation model is ignorance of influence of other components in the hydraulic operating mechanism. On the other hand, the better resemblance in pressure curves proves the integrated simulation model reliable. Meanwhile, the CFD model can be helpful for analyzing the flow field in cushion chamber.

\section{Optimal Design of Key Structural Parameters}

The hydraulic shock in hydraulic cylinder can be relieved by reasonable cushion structure and optimal design. The lower the hydraulic shock is, the more impulsive load caused by the hydraulic shock can be reduced to improve the kinematic accuracy and reliability of UHV circuit breaker. In the industry design of hydraulic cylinder, the main concern is the plunger structure and some key structural parameters such as diameter of cushion hole, length, and diameter of plunger. Through following study of structural parameters, the optimal scheme is presented to promote the original cushion performance of hydraulic cylinder.

From the comparison of different simulation models, the integrated model of hydraulic operating mechanism can reveal the whole working condition of UHV circuit breaker with less error. Therefore, the integrated model is utilized to research the cushion performance of hydraulic cylinder.

4.1. Option of Cushion Plunger Structure. In theoretical design of plunger, there are three main structures, as cylinder, cone, and parabola. In the meantime, the initial gap between the head of plunger and cushion hole is the main structure 
TABLE 2: Advantages and disadvantages of the three simulation models.

\begin{tabular}{lll}
\hline Simulation model & Advantages & Disadvantages \\
\hline Lumped parameter model & $\begin{array}{l}\text { (1) Fast modeling time } \\
\text { (2) Fast calculating time (about 1 min) }\end{array}$ & $\begin{array}{l}\text { (1) Low accuracy on both values and } \\
\text { tendency }\end{array}$ \\
\hline & $\begin{array}{l}\text { (1) Normal calculating time (about 30 min) } \\
\text { (2) High similarity to the values of the test data } \\
\text { Integrated model }\end{array}$ & $\begin{array}{l}\text { (1) Long modeling time (need to consider } \\
\text { all the components of hydraulic system) } \\
\text { process }\end{array}$ \\
\hline & $\begin{array}{l}\text { (1) Normal modeling time } \\
\text { (2) High similarity to the test tendency of cushion } \\
\text { process } \\
\text { (3) Disclosure of the flow pattern during cushion } \\
\text { process }\end{array}$ & $\begin{array}{l}\text { (1) Long calculating time (about 40 h) } \\
\text { to test data }\end{array}$ \\
\end{tabular}

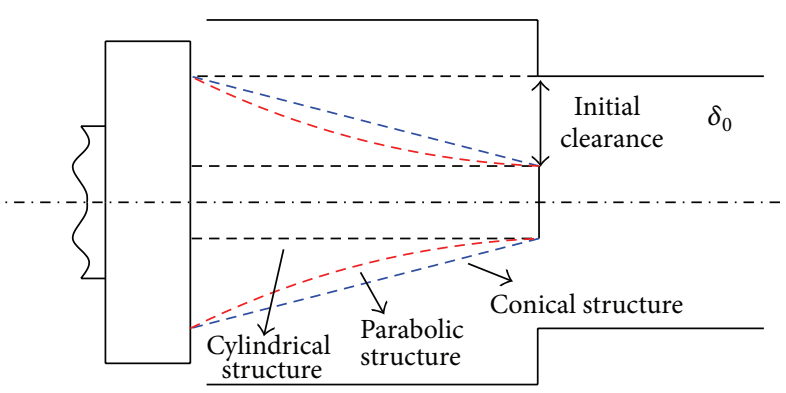

FIGURE 20: Schematic diagrams of the three-plunger structure.

parameter affecting the cushion performance. Taking the three main plunger structures as study object, the comparison of cushion performances is analyzed with variation of gap.

The schematic diagram of the three-plunger structure is shown in Figure 20. According to the parameter of actual product, the value of gap is set between $1 \mathrm{~mm}$ and $2 \mathrm{~mm}$. The optimal structure needs to have less cushion peak pressure, proper cushion time, slower cushion final velocity, and no reverse impact.

The cushion performance of different plunger structure is shown in Figures 21, 22, and 23.

The bigger gap with cylindrical structure can reduce the peak cushion pressure. However, the cushion final velocity keeping a high value will cause huge impact to the hydraulic cylinder.

The conical structure can have less cushion peak pressure and lower final velocity with proper change of gap. When the gap is $1.4 \mathrm{~mm}$, the peak pressure drops are $45.85 \%$ and the final velocity drops are $60 \%$ compared to the original value.

In addition, the parabolic structure can also have less cushion peak pressure with proper gap value. Nevertheless, the final velocity remaining around $2 \mathrm{~m} / \mathrm{s}$ still causes a certain extent of impact.

With comprehensive analysis, the conical structure has better cushion performance with proper gap value which can be utilized in industry product.

\subsection{Influence of Structure Parameter on the Cushion Perfor-} mance. Although the conical structure has better cushion performance, the cushion plunger in practical application of the industry generally applies step structure to approach
TABLE 3: Parameters and their levels.

\begin{tabular}{lcccc}
\hline Parameter & Symbol & Level 1 & Level 2 & Level 3 \\
\hline $\begin{array}{l}\text { Diameter of } \\
\text { cushion hole } \\
(\mathrm{mm})\end{array}$ & $A$ & 50 & 60 & - \\
$\begin{array}{l}\text { Length of } \\
\text { plunger }(\mathrm{mm})\end{array}$ & $B$ & 80 & 85 & 90 \\
$\begin{array}{l}\text { Diameter of } \\
\text { plunger }(\mathrm{mm})\end{array}$ & $\mathrm{C}$ & 85 & 90 & 95 \\
\hline
\end{tabular}

proper structure considering the processing craft and cost. In order to offer available design schemes, the original step structure is taken as study object by applying Taguchi method for analysis $[20,21]$. The length of plunger $L_{0}$, diameter of cushion hole, and diameter of plunger were selected as control factors to analyze the influence of structure parameters on the cushion performance and their levels are listed in Table 3. The most suitable orthogonal array $L_{18}\left(2^{1} \times 3^{2}\right)$ was selected to determine the optimal cushion performance and to analyze the effects of structural parameters [22].

The peak pressure $P_{\max }$ and final velocity $V_{\text {end }}$ are taken as output variables. The results of simulation calculation and $S / N$ ratio values are listed in Table 4 . In this study, the goal of optimization is to minimize the peak pressure and final velocity. Therefore the lower-the-better quality characteristic is selected among the three kinds of quality characteristics as shown in

$$
\eta=\frac{S}{N_{S}}=-10 \log \left[\frac{1}{n} \sum_{i=1}^{n} y_{i}^{2}\right],
$$

where $y_{i}$ is the observed data at the $i$ th test and $n$ is the number of observations of the experiment [23].

Analysis of the effect of each control factor on the peak pressure and final velocity is performed in Table 5. This table, which is made by using the Taguchi technique, shows the optimal levels of control factors for the optimal peak pressure and final velocity.

The level values of control factors for $P_{\max }$ and $V_{\text {end }}$ given in Table 5 are shown in graph forms in Figures 24 and 25. Optimal structure parameters of the control factors for minimizing the peak pressure and final velocity can be easily 

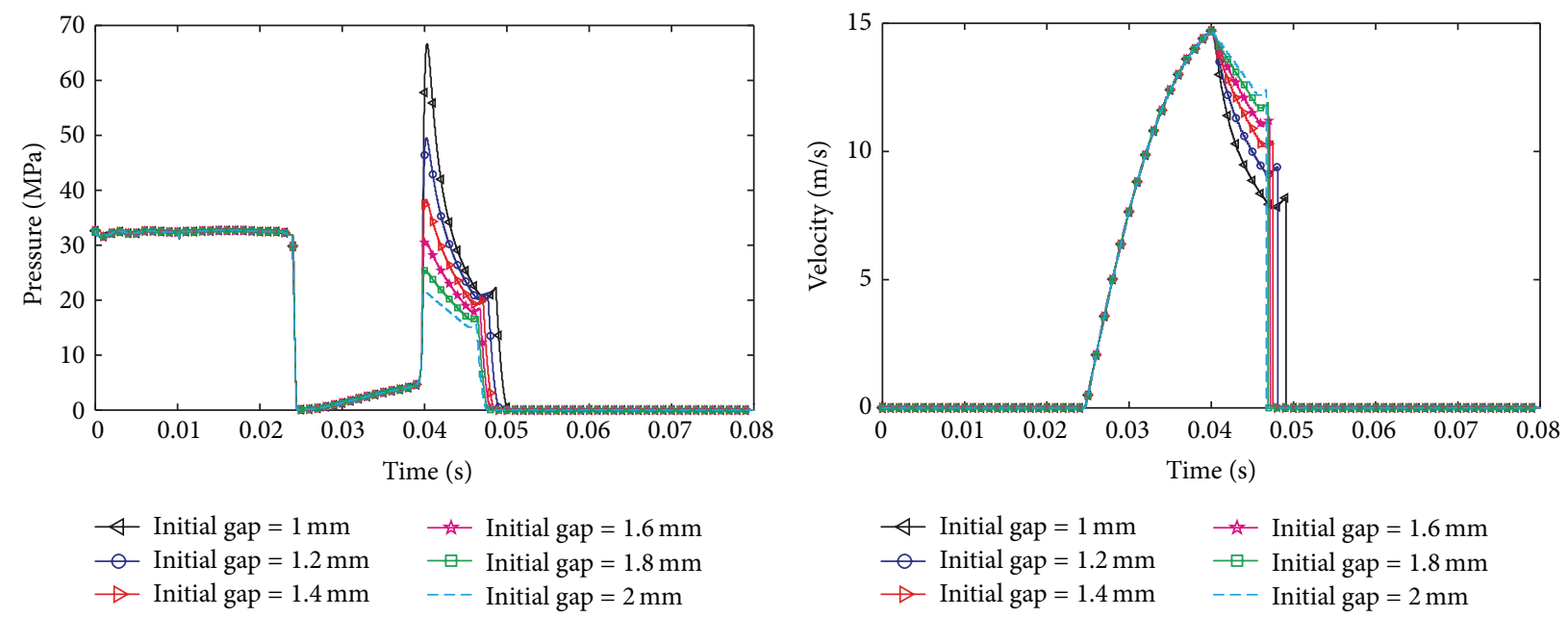

(a) Pressure

(b) Velocity

FIGURE 21: Cushion performance of cylindrical structure.

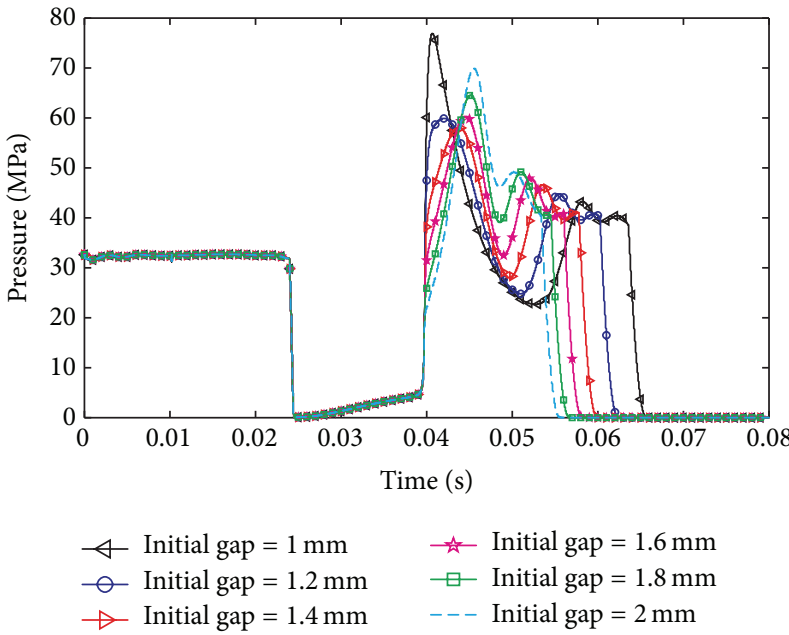

(a) Pressure

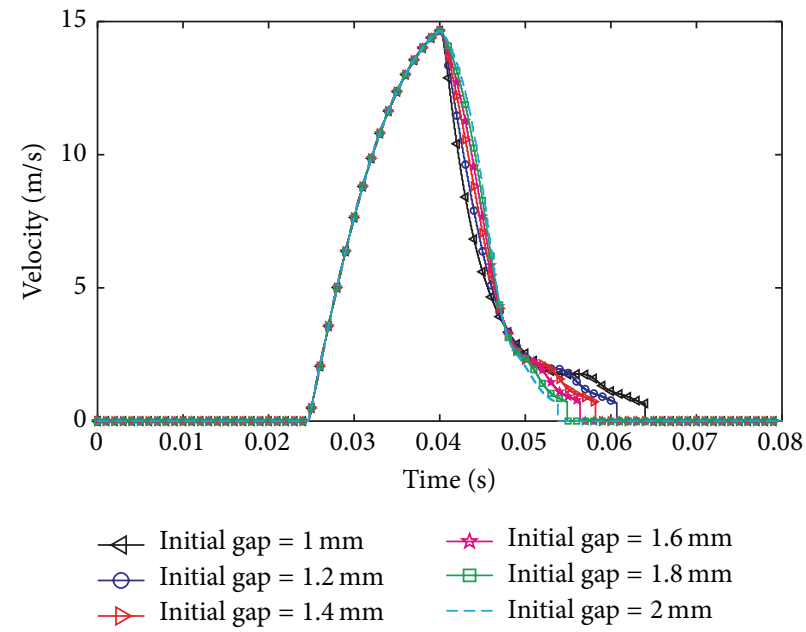

(b) Velocity

FIGURE 22: Cushion performance of conical structure.

determined from these graphs. According to this, the levels and $S / N$ ratios for the factors giving the best $P_{\max }$ value were specified as factor $A$ (Level 2, $S / N=-35.819$ ), factor $B$ (Level $3, S / N=-35.346)$, and factor $C$ (Level 3, $S / N=-34.846)$. Similarly, the levels and $S / N$ ratios for the factors giving the best $V_{\text {end }}$ value were specified as factor $A$ (Level $1, S / N=$ 0.776 ), factor $B$ (Level $2, S / N=3.369$ ), and factor $C$ (Level 3, $S / N=2.283)$.

The changes in the peak pressure and final velocity were obtained from the Taguchi orthogonal simulation as shown in Figures 26 and 27, respectively.

In peak pressure, the larger diameter of cushion hole displays an advantage over the smaller one. However, there is not much change in the final velocity affected by the diameter of cushion hole. This can be explained by the fact that the diameter of cushion hole mainly affects the process of local pressure loss stage which reduces the peak pressure and has weak influence on the final velocity. In the meantime, the length of plunger shows contrast tendencies of effect on peak pressure and final velocity. One possible reason for this is that the pressure reduces in a quite short time while the plunger reaches the end without enough time in this case. This leads to quick decreases in pressure while the velocity has not changed much. As for the diameter of plunger, the larger value will decrease the peak pressure and final velocity. This is because the diameter of plunger influences the whole cushion process which is related to the peak pressure and final velocity as shown in (10)-(11).

In order to further analyze the effects of diameter of cushion hole, length of plunger, and diameter of plunger on peak pressure and final velocity, ANOVA method is applied to determine the individual interactions of all the control factors [24]. The ANOVA results for the peak pressure and final velocity are shown in Table 6. 
TABLE 4: The results of simulation calculation and $S / N$ ratios values.

\begin{tabular}{|c|c|c|c|c|c|c|c|}
\hline \multirow{2}{*}{$\begin{array}{l}\text { Calculation } \\
\text { number }\end{array}$} & \multicolumn{3}{|c|}{ Control factors } & \multirow{2}{*}{$\begin{array}{c}\text { Peak pressure, } \\
P_{\max }(\mathrm{MPa})\end{array}$} & \multirow{2}{*}{$\begin{array}{c}S / N \text { ratio for } \\
P_{\max }(\mathrm{dB})\end{array}$} & \multirow{2}{*}{ Final velocity, $V_{\text {end }}(\mathrm{m} / \mathrm{s})$} & \multirow{2}{*}{$S / N$ ratio for $V_{\text {end }}(\mathrm{dB})$} \\
\hline & $A$ & $B$ & C & & & & \\
\hline 1 & 50 & 80 & 85 & 75.416 & -37.5493 & 0.798 & 1.959 \\
\hline 2 & 50 & 80 & 90 & 62.152 & -35.869 & 0.737 & 2.650 \\
\hline 3 & 50 & 80 & 95 & 60.692 & -35.667 & 0.593 & 4.538 \\
\hline 4 & 50 & 80 & 85 & 68.866 & -36.760 & 0.737 & 2.650 \\
\hline 5 & 50 & 85 & 90 & 58.312 & -35.315 & 0.718 & 2.877 \\
\hline 6 & 50 & 90 & 95 & 59.477 & -35.487 & 0.562 & 5.005 \\
\hline 7 & 50 & 80 & 90 & 63.344 & -36.034 & 2.099 & -6.440 \\
\hline 8 & 50 & 85 & 95 & 55.056 & -34.816 & 1.562 & -3.873 \\
\hline 9 & 50 & 90 & 85 & 58.683 & -35.370 & 1.316 & -2.385 \\
\hline 10 & 60 & 80 & 85 & 83.673 & -38.452 & 0.851 & 1.401 \\
\hline 11 & 60 & 85 & 85 & 64.321 & -36.167 & 0.748 & 2.521 \\
\hline 12 & 60 & 90 & 90 & 54.053 & -34.656 & 0.598 & 4.465 \\
\hline 13 & 65 & 80 & 90 & 75.77 & -37.589 & 0.846 & 1.452 \\
\hline 14 & 65 & 85 & 95 & 59.404 & -35.476 & 0.713 & 2.938 \\
\hline 15 & 65 & 90 & 85 & 51.099 & -34.168 & 0.544 & 5.288 \\
\hline 16 & 60 & 85 & 95 & 73.153 & -37.284 & 2.361 & -7.461 \\
\hline 17 & 60 & 90 & 85 & 55.215 & -34.841 & 1.786 & -5.037 \\
\hline 18 & 60 & 95 & 90 & 48.598 & -33.732 & 1.448 & -3.215 \\
\hline
\end{tabular}

$T_{P_{\max }}$ (peak pressure total mean value) $=62.62689 \mathrm{MPa}$.

$T_{P_{\max }-S / N}$ (peak pressure $S / N$ ration total mean value $)=-35.846 \mathrm{~dB}$.

$T_{V_{\text {end }}}$ (final velocity total mean value) $=1.057 \mathrm{~m} / \mathrm{s}$.

$T_{V_{\text {end }}-S / N}$ (final velocity $S / N$ ratio total mean value $)=0.519 \mathrm{~dB}$.

TABLE 5: $S / N$ response table for $P_{\max }$ and $V_{\text {end }}$ factor.

\begin{tabular}{lccccc}
\hline & & & \multicolumn{2}{c}{ Control factors } & \multicolumn{2}{c}{ Final velocity $\left(V_{\text {end }}\right)$} \\
Levels & $A$ & Peak pressure $\left(P_{\max }\right)$ & $C$ & $A$ & $B$ \\
\hline Level 1 & -35.874 & -36.393 & -37.278 & $\mathbf{0 . 7 7 6}$ & 2.923 \\
Level 2 & -35.819 & -35.799 & -35.414 & 0.262 & -1.073 \\
Level 3 & & $-\mathbf{3 5 . 3 4 6}$ & $\mathbf{- 3 4 . 8 4 6}$ & & $\mathbf{3 . 3 6 9}$ \\
\hline
\end{tabular}

Note: bold values show the best value of control factors.

TABLE 6: Results of ANOVA for $P_{\max }$ and $V_{\text {end }}$.

\begin{tabular}{|c|c|c|c|c|c|}
\hline Variance source & Degrees of freedom (DOF) & Sum of squares (SS) & Mean square (MS) & $F$ ratio & Contribution rate $(\%)$ \\
\hline \multicolumn{6}{|l|}{$P_{\max }$} \\
\hline$A$ & 1 & 0.6006 & 0.600608 & 0.02921 & 0.04 \\
\hline$B$ & 2 & 180.3238 & 90.16191 & 4.385009 & 11.97 \\
\hline$C$ & 2 & 1078.609 & 539.3044 & 26.22897 & 71.61 \\
\hline Error & 12 & 246.7368 & 20.5614 & - & 16.38 \\
\hline Total & 17 & 1506.27 & - & - & 100 \\
\hline \multicolumn{6}{|l|}{$V_{\text {end }}$} \\
\hline A & 1 & 0.0332 & 0.0332 & 1.2455 & 0.61 \\
\hline$B$ & 2 & 4.4831 & 2.2415 & 84.1031 & 82.8 \\
\hline C & 2 & 0.5783 & 0.2891 & 10.8481 & 10.68 \\
\hline Error & 12 & 0.3198 & 0.0267 & - & 5.91 \\
\hline Total & 17 & 5.4144 & - & - & 100 \\
\hline
\end{tabular}




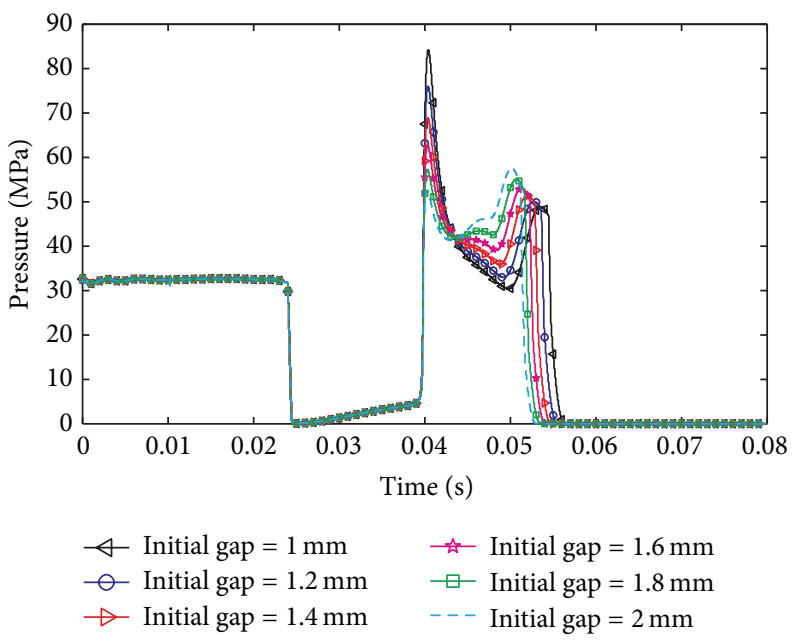

(a) Pressure

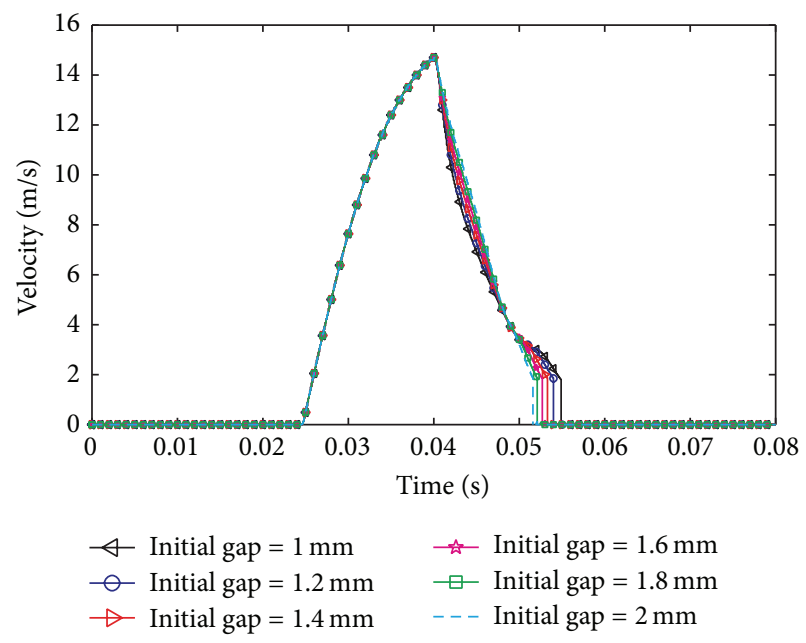

(b) Velocity

FIGURE 23: Cushion performance of parabolic structure.
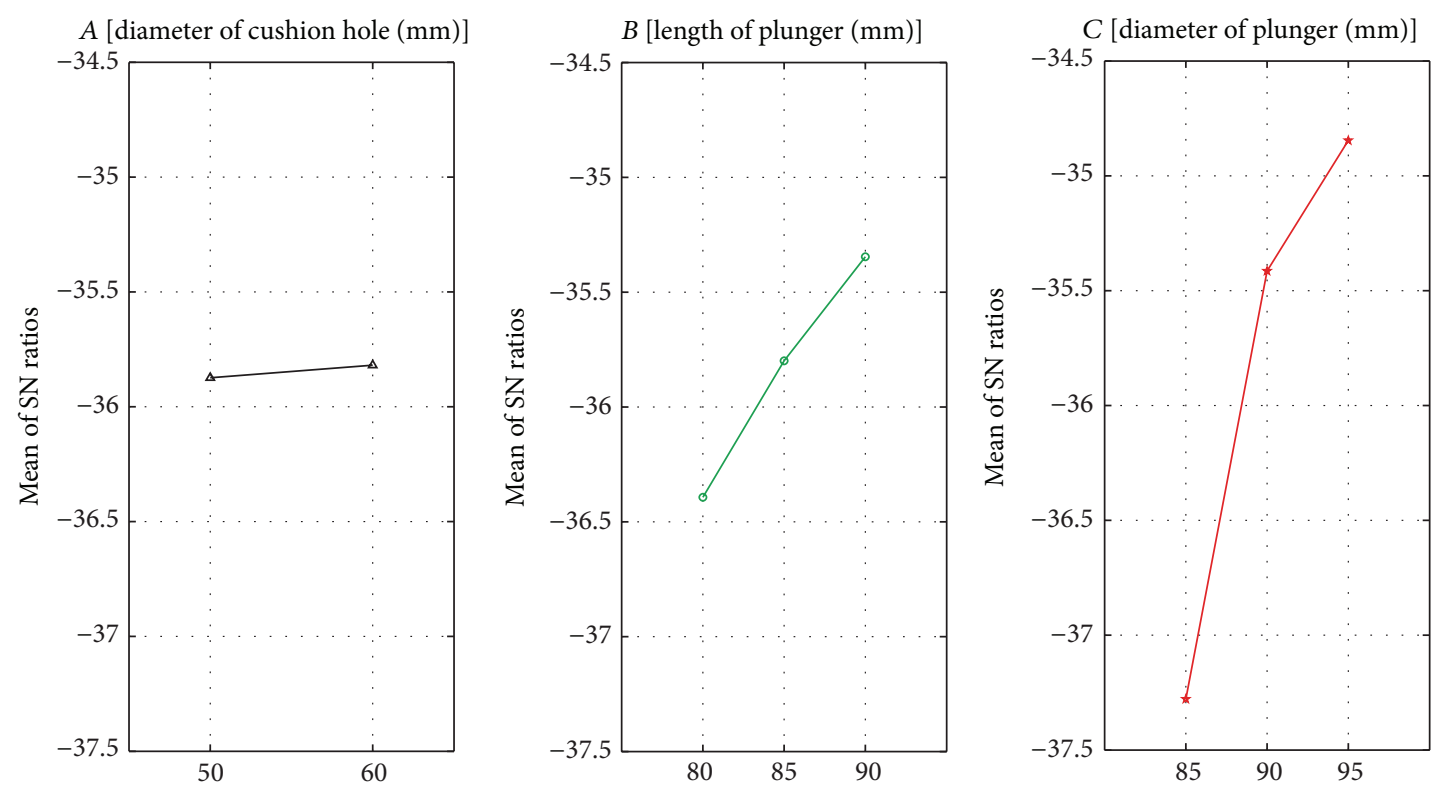

FIgURE 24: Effect of structure parameters on average $S / N$ ratio for $P_{\max }$.

A 95\% confidence level is carried out to identify the control parameters that affect peak pressure and final velocity. The significance of control factors in ANOVA is determined by comparing the $F$ values of each control factor. The last column of the table shows the percentage value of each parameter contribution which indicates the degree of influence on peak pressure and final velocity. According to Table 6 , the percent contribution of factors $A, B$, and $C$ on peak pressure is $0.04 \%, 11.97 \%$, and $71.61 \%$, respectively. This shows that the most effective factor on peak pressure is diameter of plunger. Similarly, the percent contribution of factors $A, B$, and $C$ on final velocity is $0.61 \%, 82.8 \%$, and $10.68 \%$, respectively. Thus, the most important factor affecting the final velocity is length of plunger.
The variable $C$ (diameter of plunger) has the most impact on the cushion pressure and final velocity, whereas the cushion pressure and final velocity cannot reach the optimal value as each influential tendency is contrary. Thus each parameter should be considered in practical design of plunger structure to prove lower pressure with less final velocity.

From the analysis of different plunger structures and structural parameters, the conical structure has better cushion performance with proper design. Through different optimal design schemes, one with $85 \mathrm{~mm}$ length of plunger, $50 \mathrm{~mm}$ diameter of cushion hole, and $95 \mathrm{~mm}$ diameter of plunger has the best cushion effect as shown in Figure 28. The optimal scheme lowers $45.19 \%$ of the peak pressure and lowers $59.12 \%$ of the final velocity. 

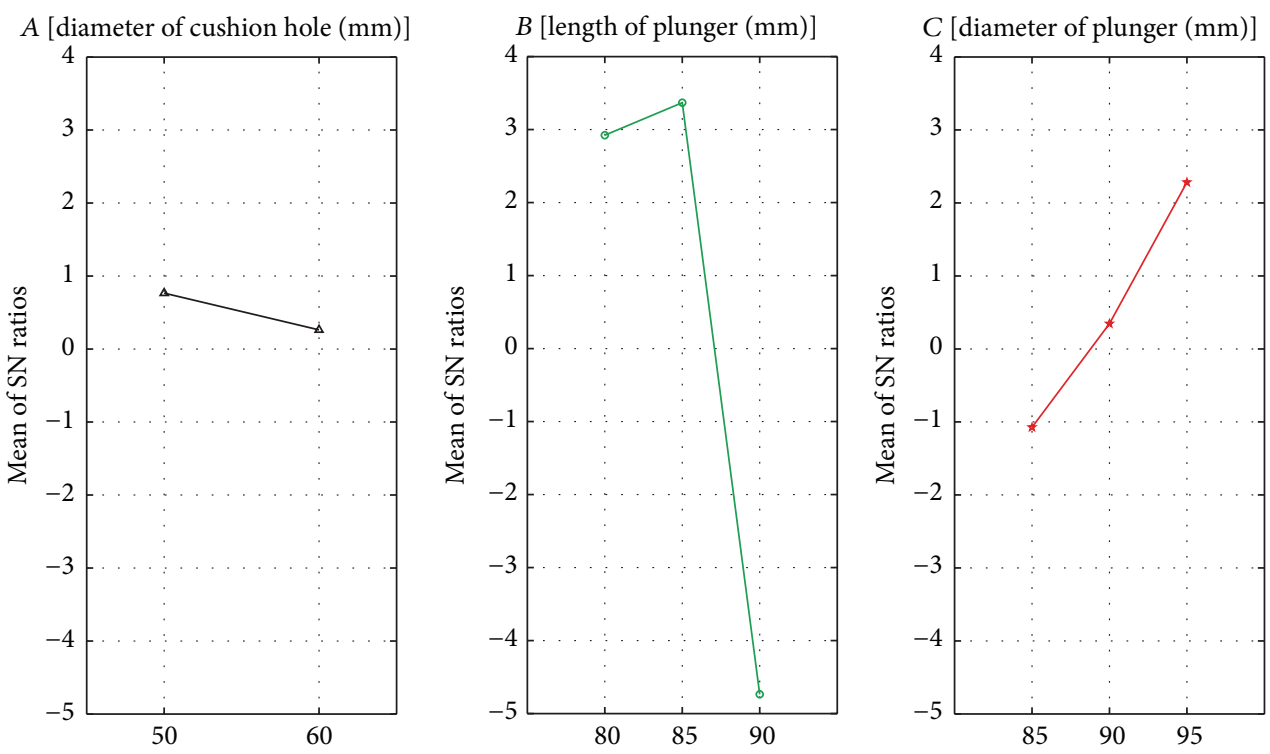

FIGURE 25: Effect of structure parameters on average $S / N$ ratio for $V_{\text {end }}$.
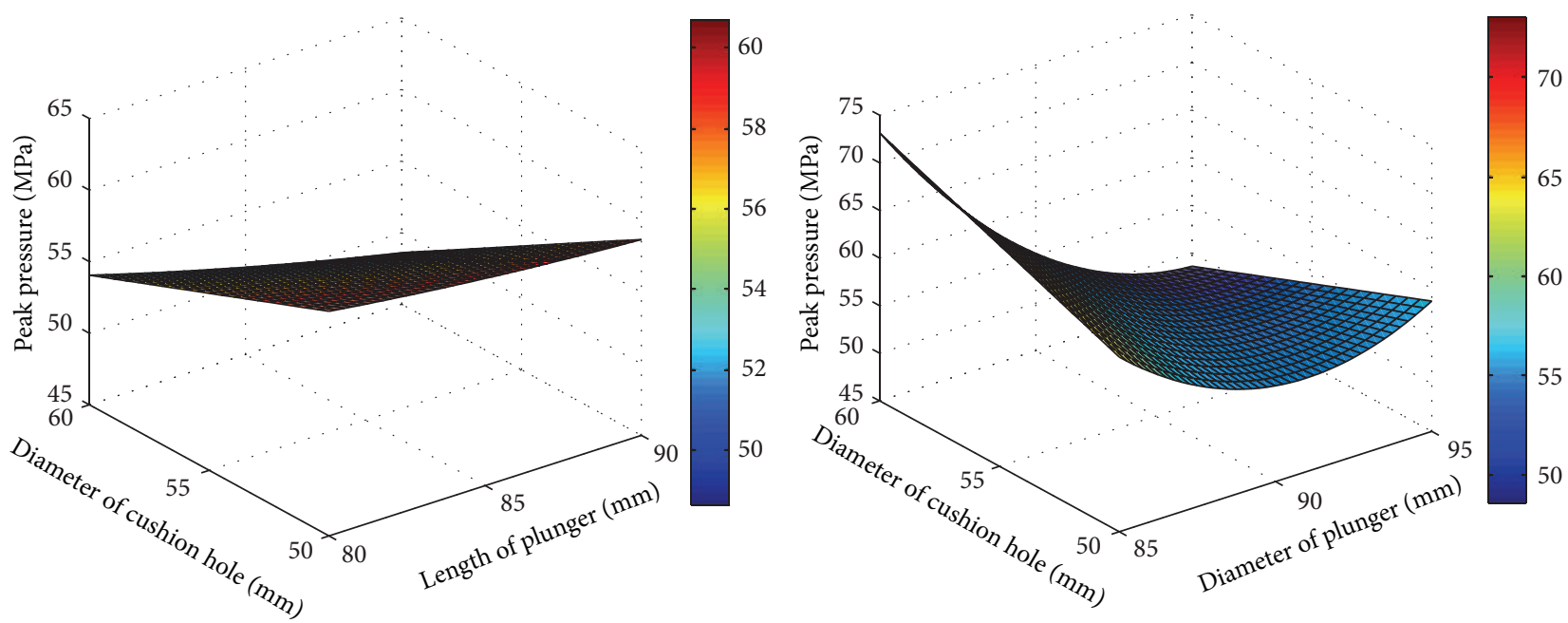

FIgURE 26: Effect of structure parameters on $P_{\max }$.
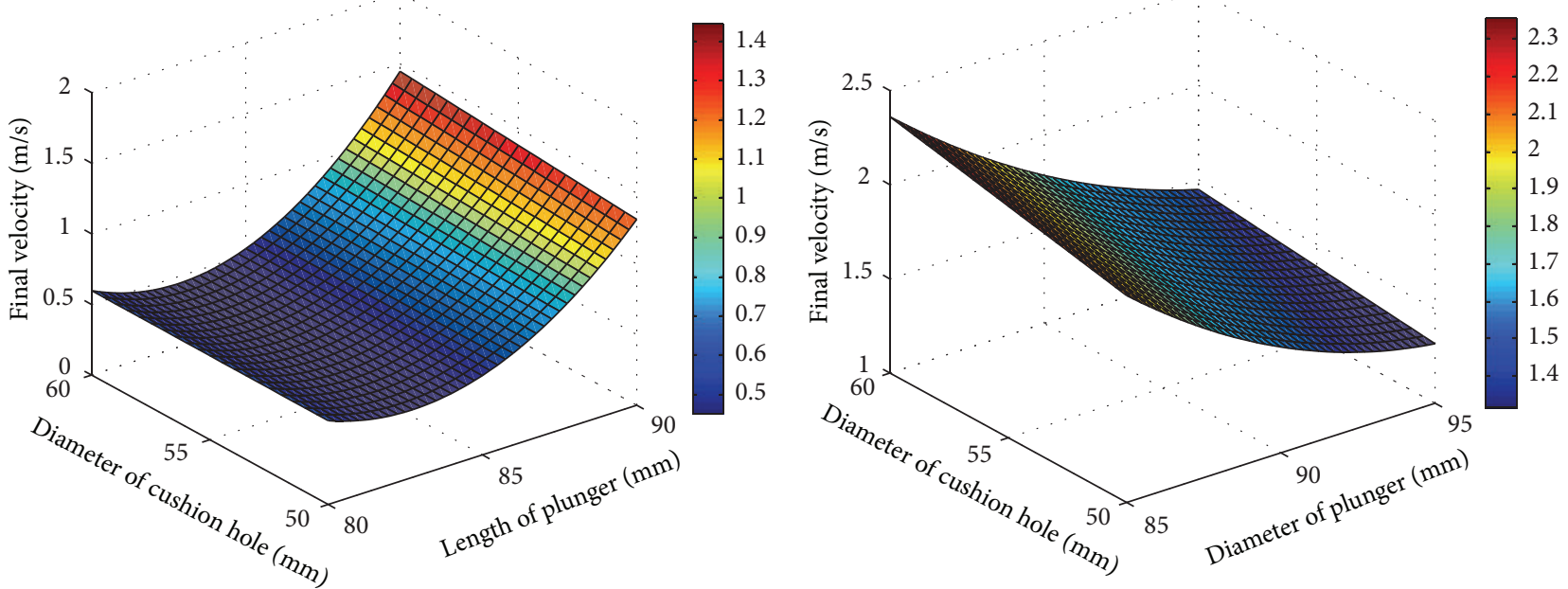

FIGURE 27: Effect of structure parameters on $V_{\text {end }}$. 


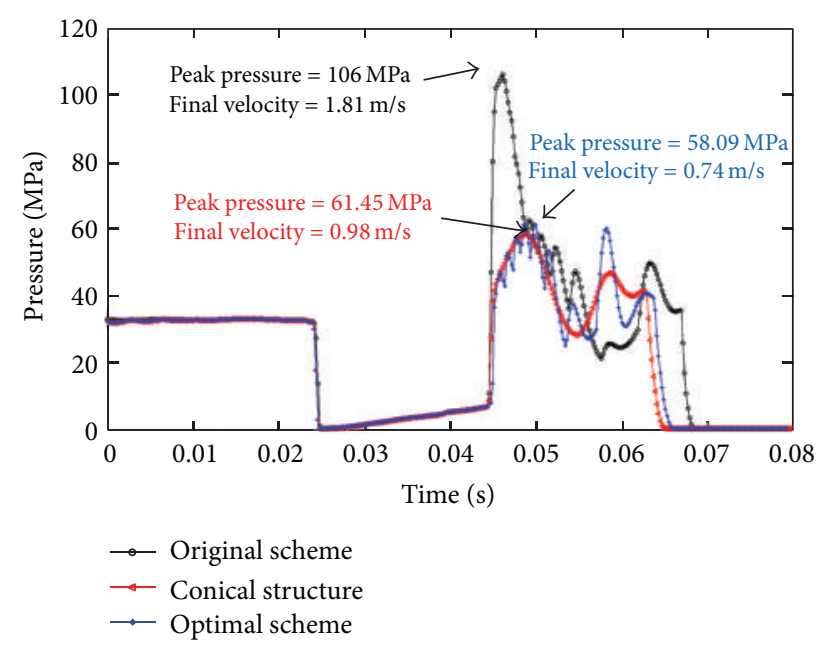

FIGURE 28: Cushion effects from different schemes.

\section{Conclusions}

Within this paper, a fast and high-flow-rate hydraulic cylinder applied in large transient power hydraulic system is presented to analyze the cushion characteristics with three different simulation models. Experiments results are obtained to verify the reasonability of different models. The following conclusions are obtained from the comparisons between different simulation models and analysis of cushion characteristics:

(1) The integrated simulation model of the hydraulic system has better engineering application value with less error compared with lumped parameter model and CFD model. However, the CFD model can reveal the cushion process more precisely than the other models.

(2) The conical cushion plunger structure has better cushion performance with proper design than the column and parabolic structure.

(3) The diameter of cushion hole and length of plunger have different effects on the peak pressure and final velocity during cushion process while the bigger diameter of plunger has positive function to lower the peak pressure and final velocity. Therefore, the value of diameter of cushion hole and length of plunger should be designed by considering peak pressure and final velocity comprehensively. Optimal scheme of cushion structure can lower about $50 \%$ of the peak pressure and final velocity.

Although the three different modeling methods can be effective in studying the fast and high-flow-rate hydraulic cylinder, there still exit some errors by ignoring the complexity of transition from different stages during cushion process. Also, more structural parameters can be considered to promote the cushion performance. Our next work will perform a further study of the principle of cushion process with interaction of different stages.

\section{Competing Interests}

The authors declare that they have no competing interests.

\section{Acknowledgments}

The authors would like to express sincere gratitude to the National Natural Science Foundation of China "Research on Load Sharing Characteristics of High-Power and Heavyload Compound Planetary Gear Transmission System (no. 51375350)" and "Theory and Methods of Incomplete Feature Reconstruction in Measurement Point Cloud Data (no. 51305307).”

\section{References}

[1] M. Tajjudin, N. Ishak, H. Ismail, M. H. F. Rahiman, and R. Adnan, "Optimized PID control using Nelder-Mead method for electro-hydraulic actuator systems," in Proceedings of the IEEE Control and System Graduate Research Colloquium (ICSGRC '11), pp. 90-93, Shah Alam, Malaysia, June 2011.

[2] N. Ishak, N. M. Yusof, W. N. A. W. Azahar, R. Adnan, and M. Tajudin, "Model identifiction and controller design of a hydraulic cylinder based on pole placement," in Proceedings of the IEEE 11th International Colloquium on Signal Processing \& Its Applications (CSPA '15), pp. 198-202, Kuala Lumpur, Malaysia, March 2015.

[3] W. Sochacki, "Modelling and analysis of damped vibration in hydraulic cylinder," Mathematical \& Computer Modelling of Dynamical Systems, vol. 21, no. 1, pp. 23-37, 2015.

[4] E. Jalayeri, A. Imam, and N. Sepehri, "A throttle-less single rod hydraulic cylinder positioning system for switching loads," Case Studies in Mechanical Systems and Signal Processing, vol. 1, pp. 27-31, 2015.

[5] J. Grabbel and M. Ivantysynova, "An investigation of swash plate control concepts for displacement controlled actuators," International Journal of Fluid Power, vol. 6, no. 2, pp. 19-36, 2005.

[6] M. Linjama, K. T. Koskinen, and M. Vilenius, "Accurate trajectory tracking control of water hydraulic cylinder with non-ideal on/off valves," International Journal of Fluid Power, vol. 4, no. 1, pp. 7-16, 2003.

[7] D. Boehm, C. Hollander, and T. Landmann, "Hybrid drives in crawler excavators: concepts and solutions," in Proceedings of the 3rd Symposium on Hybrid Drive Systems for Mobile Machinery, pp. 117-124, 2011.

[8] D. N. C. Nam, J. I. Yoon, and K. K. Ahn, "Position control of electro hydrostatic actuator (EHA) using a modified back stepping controller," Journal of the Korean Society for Fluid Power \& Construction Equipments, vol. 9, no. 3, pp. 16-22, 2012.

[9] X. Chen, F. Chen, J. Zhou, L. Li, and Y. Zhang, "Cushioning structure optimization of excavator arm cylinder," Automation in Construction, vol. 53, pp. 120-130, 2015.

[10] A. Świątoniowski, J. Szostak, and K. Gomułka, "Analysis forming the diameter reduction of the tube to the cylinder hydraulic shock absorber," Journal of KONES, vol. 21, no. 1, pp. 281-286, 2014.

[11] S. Cantelli and R. Paoluzzi, "Numerical and experimental analysis of hydraulic cylinders cushioning design (Geometry II)," Prohipp Report, 2007. 
[12] C.-K. Teng, C.-Y. Hsiao, and C.-S. Wang, "The effect of the guiding directions of the guiding cylinders of an area ratio modified machine cushion on the capability of suppressing impact and vibration," Advances in Engineering Software, vol. 40, no. 10, pp. 991-999, 2009.

[13] C.-K. Teng, C.-Y. Hsiao, and C.-S. Wang, "Effects of an absorber on impact characteristics in machine cushion design with area ratio modified guiding structure," Simulation Modelling Practice and Theory, vol. 16, no. 9, pp. 1200-1214, 2008.

[14] B. Wang, X. Jin, R. Huang, and S. Chen, "Simulation and experimental verification of a fuel calibration system based on metering cylinder," Flow Measurement and Instrumentation, vol. 38, pp. 131-138, 2014.

[15] Z. Y. Wei, H. F. Zhao, and W. Liu, "Cushion process of the hydraulic cylinder of hydraulic operating mechanism for high voltage circuit breaker," Transactions of the Chinese Society for Agricultural Machinery, vol. 44, no. 60, pp. 216-221, 2010.

[16] P. Ghadimi, A. Dashtimanesh, and S. R. Djeddi, "Study of water entry of circular cylinder by using analytical and numerical solutions," Journal of the Brazilian Society of Mechanical Sciences \& Engineering, vol. 34, no. 3, pp. 225-232, 2012.

[17] W. Liu, B. Xu, H. Yang, H. Zhao, and J. Wu, "Hydraulic operating mechanisms for high voltage circuit breakers: progress evolution and future trends," Science China Technological Sciences, vol. 54, no. 1, pp. 116-125, 2011.

[18] M. García Pérez, E. Vakkilainen, and T. Hyppänen, “2D dynamic mesh model for deposit shape prediction in boiler banks of recovery boilers with different tube spacing arrangements," Fuel, vol. 158, pp. 139-151, 2015.

[19] A. Menéndez Blanco and J. M. Fernández Oro, "Unsteady numerical simulation of an air-operated piston pump for lubricating greases using dynamic meshes," Computers \& Fluids, vol. 57, no. 4, pp. 138-150, 2012.

[20] K. Palanikumar, "Experimental investigation and optimisation in drilling of GFRP composites," Measurement, vol. 44, no. 10, pp. 2138-2148, 2011.

[21] I. Asiltürk and H. Akkuş, "Determining the effect of cutting parameters on surface roughness in hard turning using the Taguchi method," Measurement, vol. 44, no. 9, pp. 1697-1704, 2011.

[22] K. R. Ranjit, A Primer on the Taguchi Method, Competitive Manufacturing Series, 1990.

[23] N. Mandal, B. Doloi, B. Mondal, and R. Das, "Optimization of flank wear using Zirconia Toughened Alumina (ZTA) cutting tool: taguchi method and Regression analysis," Measurement, vol. 44, no. 10, pp. 2149-2155, 2011.

[24] T. Kivak, "Optimization of surface roughness and flank wear using the Taguchi method in milling of Hadfield steel with PVD and CVD coated inserts," Measurement, vol. 50, no. 1, pp. 19-28, 2014. 


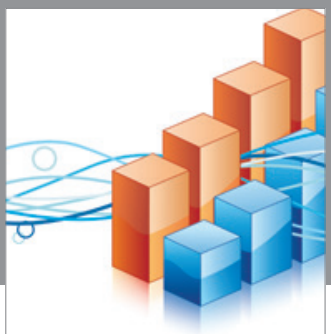

Advances in

Operations Research

vatem alat4

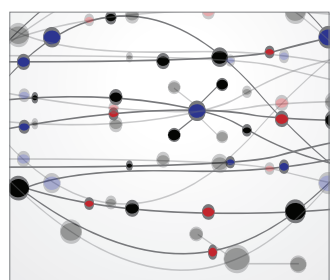

\section{The Scientific} World Journal
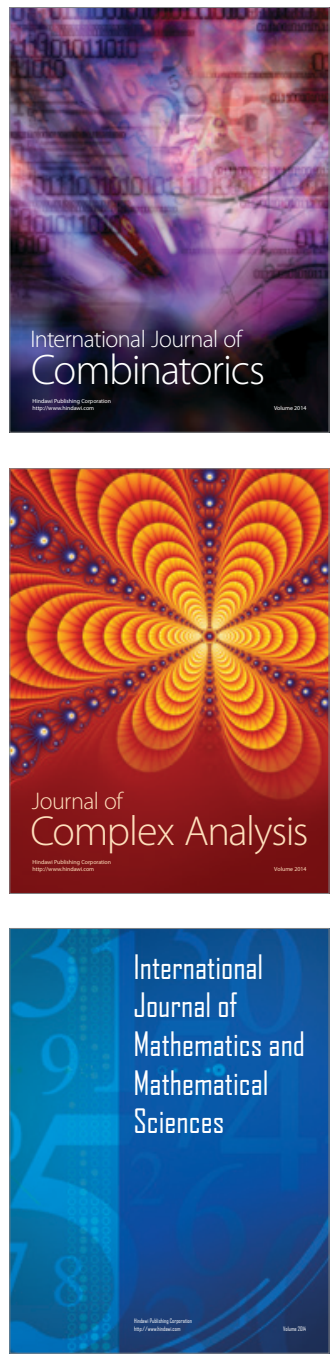
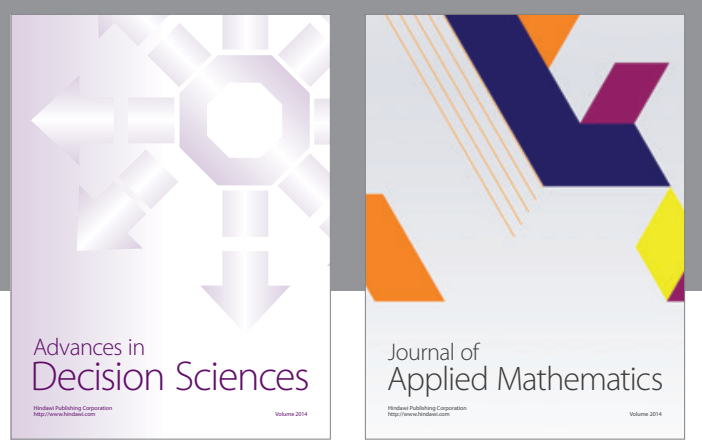

Algebra

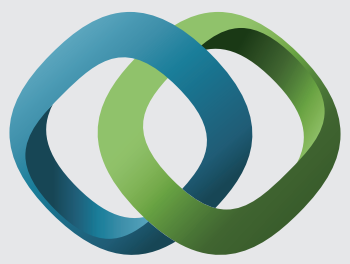

\section{Hindawi}

Submit your manuscripts at

http://www.hindawi.com
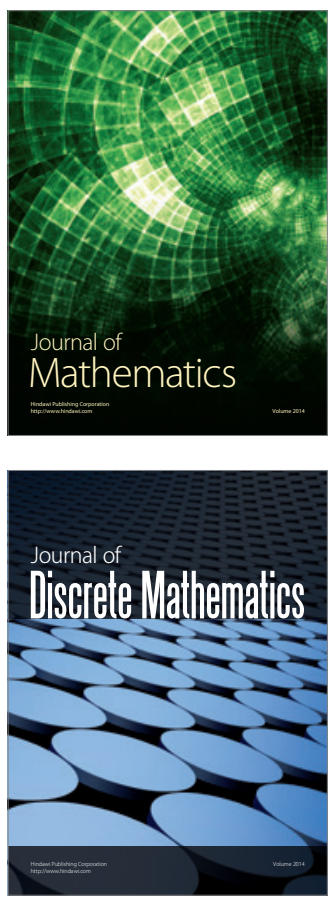

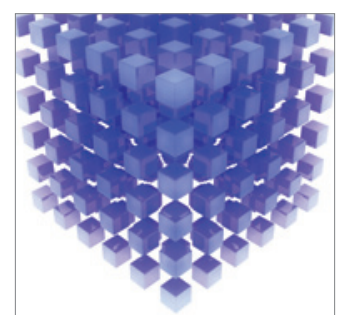

Mathematical Problems in Engineering
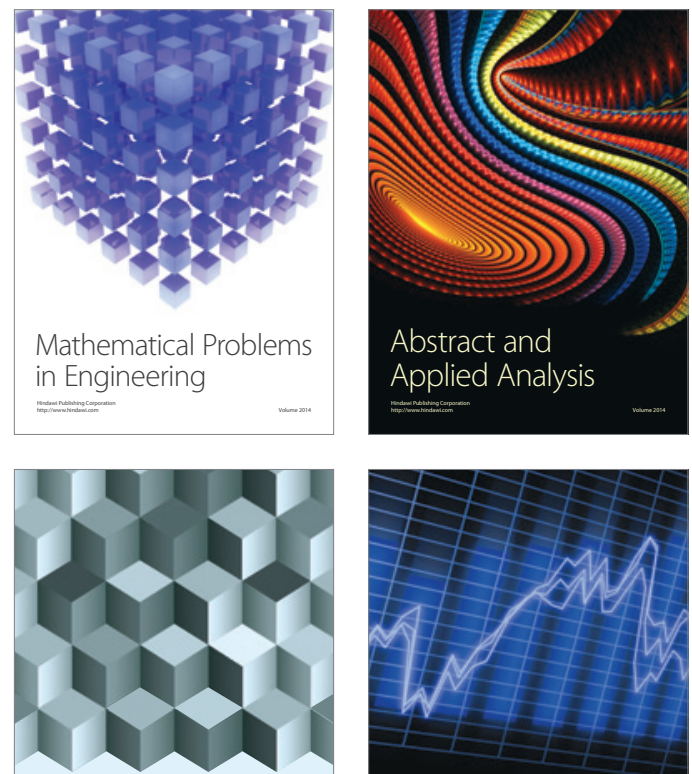

Journal of

Function Spaces

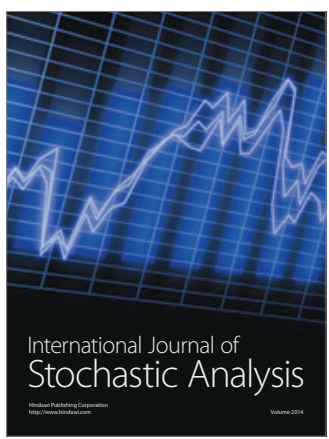

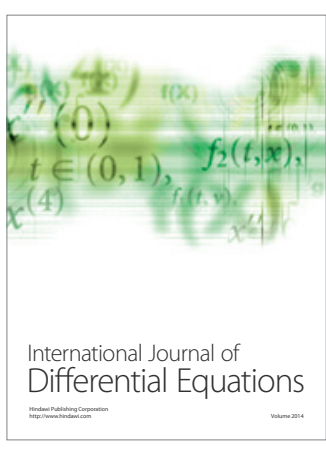
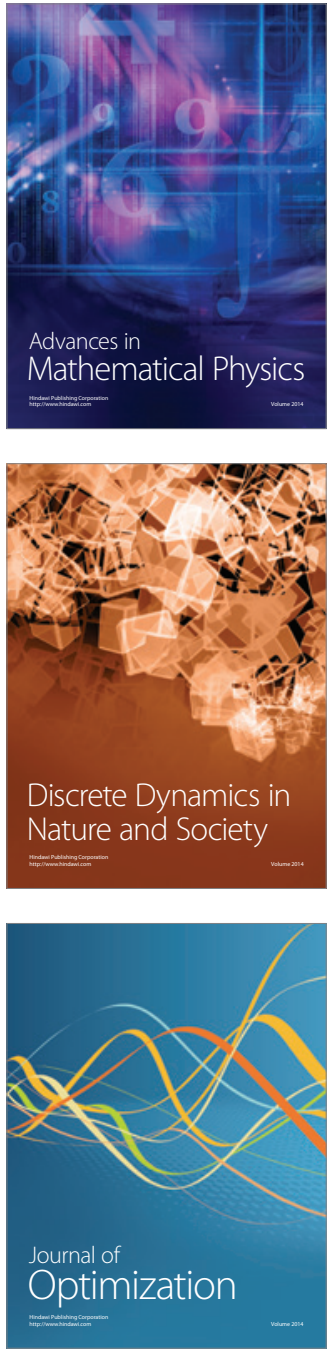